
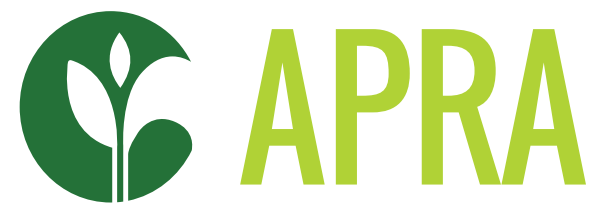

Agricultural Policy Research in Africa

\title{
THE POLITICAL ECONOMY OF THE GROUNDNUT VALUE CHAIN IN MALAWI: ITS RE-EMERGENCE AMIDST POLICY CHAOS, STRATEGIC NEGLECT, AND OPPORTUNISM
}




\section{CONTENTS}

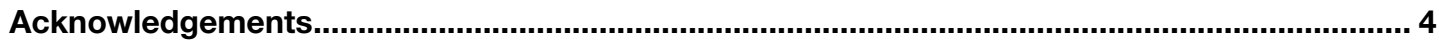

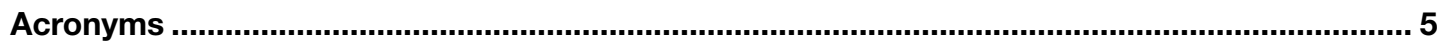

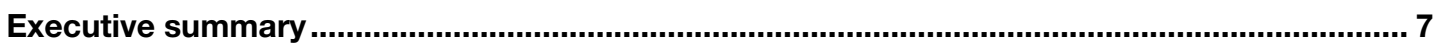

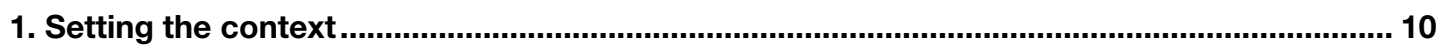

2.The conceptual and empirical underpinnings of the research ........................................... 13

2.1 Political settlement, rents and policymaking ............................................................ 13

2.2 A brief overview of Malawi's political settlement …................................................ 14

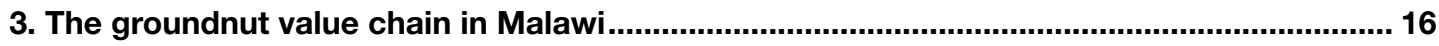

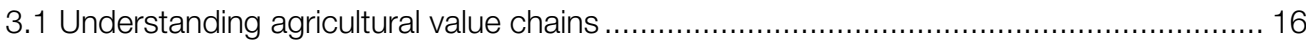

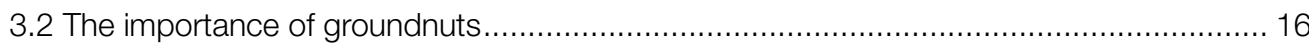

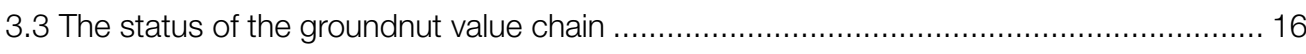

4. The re-emergence and recovery of the groundnut value chain ............................................... 26

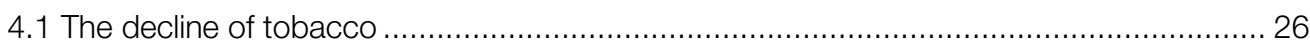

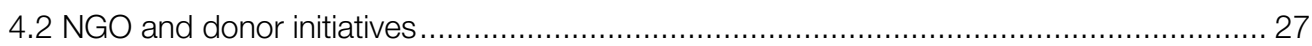

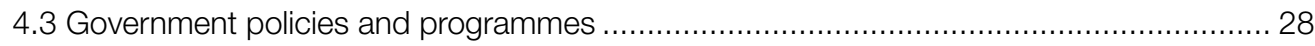

5. The strategic neglect and capture of the groundnut value chain........................................... 31

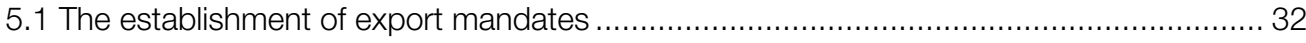

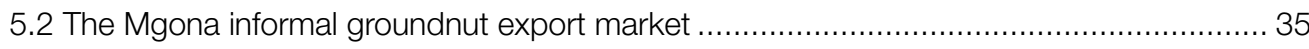

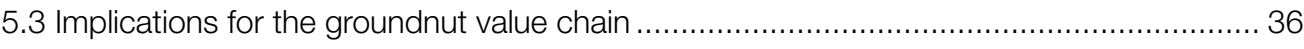

6. Social differentiation in the groundnut value chain............................................................ 38

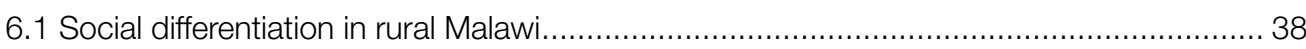

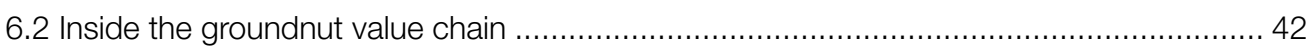

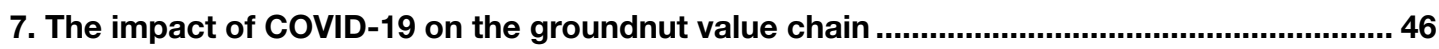

7.1 The political, economic and social context of the impacts of COVID-19 ....................... 46

7.2 The impacts of the COVID-19 pandemic on the economy ......................................... 47

7.3 The impact of COVID-19 on the agri-food sector .................................................... 48

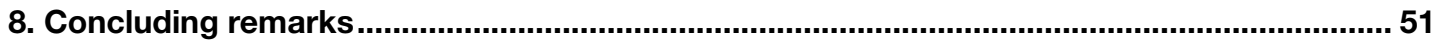

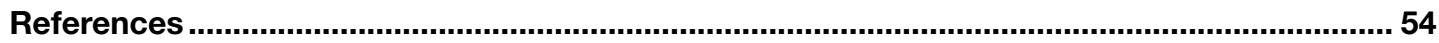

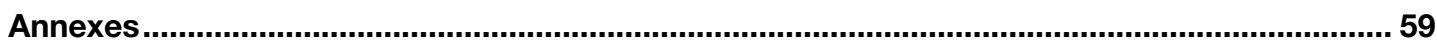

Annex 1: The hypotheses applicable to Malawi's groundnut value chain .............................. 59

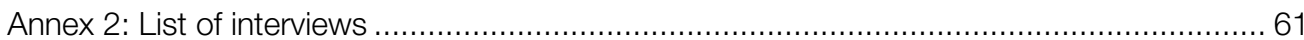


Tables

Table 3.1: Stakeholders in the groundnut value chain......................................................... 18

Figures

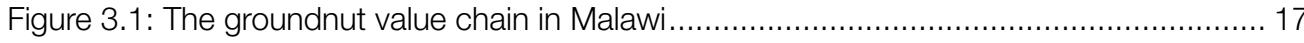

Figure 3.2: Groundnut production and export trends in Malawi (1961-2018)....................... 19 


\section{ACKNOWLEDGEMENTS}

We would like to take this opportunity to extend our debt of gratitude to all stakeholders who spared their time to be interviewed for this study. Their views, perceptions and perspectives were very useful in the preparation of this paper. Likewise, we thank both internal reviewers, namely: Helen Dancer and Lars Otto Naess, and the anonymous external reviewer, for their insightful comments on the earlier drafts of this paper. These reviews helped us to deeply reflect and further engage with emerging issues from the research, which added clarity, enhanced coherence, broadened, and deepened our analysis. We would also like to thank Susanna Cartmell-Thorp and her copy editing team for the helpful assistance they rendered in the finalisation of the paper. Last but not least, we thank the Foreign Commonwealth Development Office (FCDO), for funding the research for this study through the Agricultural Policy Research in Africa (APRA) consortium, hosted by the Institute of Development Studies at the University of Sussex, United Kingdom. All errors of interpretation remain our sole responsibility.

Blessings Chinsinga, $\mathrm{PhD}$ is the Director of the Centre for Social Research and Professor at the Department of Political and Administrative Studies at Chancellor College, University of Malawi. Mirriam Matita is a PhD student of Economics at Chancellor College, University of Malawi. She is also an academic at the Lilongwe University of Agriculture and Natural Resources in Malawi.

This working paper is funded with UK aid from the UK government (FCDO, formerly the Department for International Development). The opinions are the authors and do not necessarily reflect the views or policies of the Institute of Development Studies or the UK government. 


\section{ACRONYMS}

ACE

ADMARC

AGRA

AHXC

AICC

APRA

ASWAp

CAADP

CGA

EU

FCDO

FISP

FPES

FtF-INVC

FUM

GTAM

HRDC

ICRISAT

IFPRI

IMF

IPS

MAPAC

MGDS

MK

NAIP

NASFAM
Agricultural Commodity Exchange

Agricultural Development and Marketing Corporation

Alliance for a Green Revolution in Africa

Auction Holdings Commodity Exchange

Africa Institute for Corporate Citizenship

Agricultural Policy Research in Africa

Agriculture Sector Wide Approach

Comprehensive Africa Agriculture Development Programme

Control Goods Act

European Union

Foreign Commonwealth Development Office

Farm Input Subsidy Programme

Fresh Presidential Elections

Feed the Future Malawi: Integrating Nutrition in Value Chains

Farmers Union of Malawi

Grain Traders Association of Malawi

Human Rights Defenders Coalition

International Crops Research Institute for Semi-Arid Tropics

International Food Policy Research Institute

International Monetary Fund

integrated production system

Malawi Programme for Aflatoxin Control

Malawi Growth and Development Strategy

Malawian Kwacha

National Agriculture Investment Plan

National Association of Smallholder Farmers of Malawi 


$\begin{array}{ll}\text { NES } & \text { National Export Strategy } \\ \text { NGOs } & \text { non-governmental organisations } \\ \text { OPV } & \text { open pollinated variety } \\ \text { PEA } & \text { political economy analysis } \\ \text { Ppb } & \text { parts per billion } \\ \text { SADC } & \text { Southern Africa Development Community } \\ \text { SAPs } & \text { structural adjustment programmes } \\ \text { SMEs } & \text { small and medium enterprises } \\ \text { STAM } & \text { Seed Traders Association of Malawi } \\ \text { TCC } & \text { Tobacco Control Commission } \\ \text { UK } & \text { United Kingdom } \\ \text { USAID } & \text { United States Agency for International Development } \\ \text { WFP } & \text { World Food Programme }\end{array}$


This paper explores the political economy of the groundnut value chain in Malawi. The paper is based on an extensive literature review of authoritative studies of the groundnut value chain in Malawi, including recent policies and regulations that govern it. Secondary sources, particularly official statistics, were consulted to illuminate the structure and performance of the groundnut value chain. This evidence was complemented by interviews with key and influential actors in the value chain, drawn from civil society, especially farmers' organisations, government, the private sector, academia, and donor agencies. Some of these interviews provided an opportunity to discuss the political dimensions of the functioning and performance of the value chain with a particular focus on the interests and holding power of different actors and how these influence policy, practice, and outcomes.

This paper therefore uses a combination of insights from the theoretical perspectives of political settlement, rents, and policymaking to examine the groundnut value chain in Malawi. Fused together, these theoretical perspectives underpin a political economy analysis (PEA) framework, which entails systematically mapping all key actors in an issue area; identifying their interests and recognising their forms of power (political, economic, social, and ideological); understanding their relationships with each other; and appreciating the issues, narratives, and ideas that shape how and why they interact with each other. With these political economy lenses, the paper addresses the following three substantive questions and three hypotheses, respectively, to understand the status of the groundnut value chain in Malawi:

- What are the underlying dynamics of social differentiation within the groundnut value chain?

- What is the impact of climate change on the productivity and profitability of the groundnut value chain?

- What is the impact of the COVID-19 pandemic on the agri-food systems in Malawi through the experiences of the groundnut value chain?
- If the country is landlocked, engagement in the value chain by national elites takes the form of acquiring land for crop production, seeking to secure reliable market outlets and prices for their produce through manipulation of state policies, and/or orchestrating the availability of cheap inputs (e.g. fertilisers), equipment (e.g. tractors), and services that they can 'capture'.

- If production of the crop primarily takes place in sub-national regions with high population density (greater than 200 persons per km²); production and sale for market are both dominated by smallholder farmers, despite the interest of larger players in entering the value chain. Conversely, where production of the crop primarily takes place in sub-national regions with low to medium population density (less than 200 persons per km²); medium and perhaps also large-scale farms have expanded their production and marketing of the crop dramatically over the past decade.

- If traditional development partners have engaged actively with the value chain over the past decade: policy interventions have both been designed to stimulate commercialisation in some form or another and to facilitate the participation of smallholder farmers in the resulting commercialisation processes.

This study paid particular focus to the gender dimension of social differentiation in the groundnut value chain, while recognising the role of intersectionality in social differentiation. Intersectionality focuses on understanding how aspects of a person's social and political identities combine to create different modes of discrimination and privilege. The focus areas of this paper, among other aspects, are the barriers to entry and/or requirements for men and women to participate in the value chain; the differences in men's and women's ability to maintain or improve their position in the value chain; and the differences in men's and women's ability to access and control benefits from the value chain. 
This paper has demonstrated that the groundnut value chain is a potentially significant alternative to the collapsing tobacco industry, but it is currently neglected by government, while being exploited by a cartel of traders (domestic and foreign), technocrats, and politicians for selfish interests. Legumes (mainly groundnuts, soya beans, and pigeon peas) have been designated as potential replacement crops for the fledgling tobacco sector, as a leading foreign exchange earner, in the National Export Strategy (NES) (20122018). However, this strategy has not been matched with government efforts to facilitate its realisation. The mainstream narrative simply projects the groundnut value chain in Malawi as unviable because of its limited productivity. The low levels of productivity are due to the dominance of smallholder farmers in the value chain; the unattractiveness of the value chain to private sector investment, especially the groundnut seed system, which is key to improved productivity; and the inability of most producers, especially smallholder farmers, to limit aflatoxin to acceptable levels, particularly for regional export markets and beyond.

The story told in this paper explains the rise and fall of the groundnut value chain, as well as its re-emergence in a fundamentally reconstituted political, economic, and social context. Between the 1970s and 1980s, groundnuts were one of the leading cash crops exported to Europe, as well as regional markets, but this trade collapsed at the turn of the 1990s. Both production and exports of groundnuts collapsed due to the failure to contain aflatoxin contamination to acceptable levels, as demanded by the European market. Aflatoxin is regarded as a serious health hazard, which has the potential to cause liver cancer. The collapse of the groundnut value chain was exacerbated by the introduction of structural adjustment programmes (SAPs) under the auspices of the World Bank and IMF, which fundamentally changed the institutional context of the groundnut value chain (Matita 2018; Mgalamadzi 2018). The reference to SAPs is still relevant three decades or so later, largely because of the enduring legacy that the policies have had on the country's ability to drive its development agenda, which have been informed by endogenous rather than exogenous considerations.

There have been several efforts to revive the production, as well as the export, of groundnuts. These initiatives have been largely successful in terms of reviving groundnut productivity, but have failed to reclaim the share of the export market that collapsed at the turn of the 1990s. The revival in the productivity of groundnuts is attributed to several policy interventions, some of which are locally driven, while others are externally supported. However, the most notable policy in this regard is the NES (2012-2018). This strategy sought to promote legumes or oil seeds (groundnuts, soya beans, and pigeon peas) as potential alternatives to tobacco, as a leading foreign exchange earner, especially in view of the intensification of the anti-smoking lobby. The paradox, however, is that the designation of oil seeds as a potential alternative leading foreign exchange earner has not been matched by public investment to promote the progressive development of these value chains. Public investment to support, for example, ready access to seed for the crops is very limited. The existing seed system is largely supported by development partners, such as the United States Agency for International Development (USAID) and Irish Aid, which have been instrumental in the development of improved varieties. However, these improved varieties have not been made readily available to farmers.

The findings of this study demonstrate the impact of intersectionality on the welfare of women. Women are adversely affected in the groundnut value chain, not only because they are generally poorer than their male counterparts, but also because of the cultural, traditional, and social orientations that limit their sphere of action. Women are expected to carry out essentially all unpaid domestic work and they are not culturally expected to venture into economic activities that take them away from the homestead for prolonged periods without being sanctioned by the menfolk, even when they are not married. In cases where they are said to have control over land, women still cannot make critical decisions about it without deferring to their brothers, uncles, husbands, and even elder sons. The question of intersectionality applies to poorer men and youth as well. Poorer men tend to have limited access to land or are landless, usually depend on exploitative casual labour for employment, and are often disadvantaged in leadership positions, which are very key for social mobility in a context where patron-client relationships are dominant. The youth lack access to land in their own right, they cannot participate in clubs or associations, and cannot access lucrative markets when they manage to produce groundnuts. The impacts of COVID-19 have underscored the intersectionality of social differentiation, which affects the welfare of women, poorer men, and youth. These groups have not been able to access markets, even the informal ones, which have been largely monopolised by men who have better social capital networks that they can leverage in these difficult circumstances.

The study further demonstrates that there are winners and losers within the framework of the groundnut value chain, even though it is suffering neglect and only the chaotic informal markets are thriving. There is some 
contestation between and among actors with regards to the operation of export mandates, which, if properly implemented, would help to formalise commodity exports from the country. This, in turn, would enhance the proceeds that the country gets from agriculture, which are currently very low. While there seems to be general appreciation about the desirability of putting export mandates in place, there are contestations about exactly how this should be done. The positions of the key stakeholders, as discussed in this paper, show that each stakeholder group is bent on protecting their benefits, arising from the current configuration of the value chain. Behind the position of each stakeholder there are specific interests that they want to promote, either by pushing for the export mandates to operate in a particular way, or avoiding the operationalisation of the mandates altogether. The interests of the different stakeholders are further evident in the operations of the Mgona informal groundnut export market. Mgona is a thriving market despite its obvious illegality. Both traders and government officials condemn it, but no concrete action has been taken to regulate it or abandon it altogether. While farmer organisations have attempted to bring up the issue of this market and its ramifications on the commodity market, it continues to operate within a $20 \mathrm{~km}$ radius from the seat of government and in the context of a newly operationalised CGA (2017). Under this Act, a trader in agricultural commodities is required to obtain an authorisation letter from the Ministry of Agriculture before applying for a license from the Ministry of Trade. This means that any trader who imports or exports licensable goods without a requisite license commits an offense punishable by law.

The experiences of the groundnut value chain in Malawi demonstrate that agricultural policy processes are inherently political. While policies that are implemented are broadly touted as being in the interest of smallholder farmers, or indeed, farmers more broadly, stakeholders at each stage in the value chain have particular interests that they want to promote, often for selfish interests and motives. The losers are almost always the smallholder farmers. This realisation, serves to emphasise that policies are often implemented, not because they are poised to make a difference to the livelihoods of Malawians, but because they will facilitate the extraction of rents and direct benefits for the political elite (Chinsinga 2018; Cammack 2010). The significance of PEA, therefore, is that it helps to identify and understand the political, economic, and social processes that promote or block pro-poor change, as well as the role of institutions, power, and the underlying policy context.

The fate of groundnut commercialisation in Malawi is a combination of several factors, but the watershed moment remains the introduction of SAP policy prescriptions. The responses to the debilitating effects of SAPs, coupled with the culture of opportunism and corruption inherent in the competitive clientelist political settlement, has led to the re-emergence of the groundnut value chain in an informal and chaotic context. This has led to the apparent strategic neglect and consequent capture of the value chain by a cartel of politicians, technocrats, and traders (local and foreign). So, while the groundnut value chain has tremendous potential as an alternative to the fledging tobacco industry, this potential cannot be realised because of the perverse incentives that underpin Malawi's contemporary political economy. Through the groundnut value chain, this paper therefore demonstrates how different groups in society compete for and use resources, rents, and power at their disposal. The findings imply that the manner in which competition for and use of resources, rents, and power pans out, either leads to growth, transformation, and improved well-being, or stagnation and poverty (Prowse and Grassin 2020). 
This paper explores the political economy of the groundnut value chain in Malawi, building on questions and issues raised in the seminal work of the Agricultural Policy Research in Africa (APRA) consortium on the political economy of agricultural commercialisation in Africa (Poulton and Chinsinga 2018). While several questions were raised by Poulton and Chinsinga (2018), this paper zeroes in on those that are applicable and relevant to Malawi's context. These questions and issues were framed as hypotheses to shed light on the underlying drivers of and blockages to agricultural commercialisation in Africa and the details are provided in Annex 1. The paper is based on an extensive literature review of authoritative studies of the groundnut value chain in Malawi, including recent policies and regulations that govern it. Secondary sources, particularly official statistics, were consulted to illuminate the structure and performance of the groundnut value chain. This evidence was complemented by interviews with key and influential actors in the value chain, drawn from civil society, especially farmers' organisations, government, the private sector, academia, and donor agencies. Some of these interviews provided an opportunity to discuss the political dimensions of the functioning and performance of the value chain with a particular focus on the interests and holding power of different actors and how these influence policy, practice, and outcomes. $^{1}$

For the purpose of this paper, a value chain is defined as a set of interlinked activities that work to add value to a product, and consists of actors and actions that improve the product while linking commodity producers to processors and markets (Norton 2014). In examining the questions and issues of interest to this paper, the primary focus was on the institutional and governance dimensions of the groundnut value chain in Malawi. The focus was mainly on the mechanisms through which the value chain participants are organised, which relates to institutional frameworks, rents, and governance. These mechanisms are very important to understanding the power and profits held by different actors and how the power and profits are distributed, particularly for smallholder farmers (Prowse and Grassin 2020). This paper therefore uses a combination of insights from the theoretical perspectives of political settlement, rents, and policymaking to examine the groundnut value chain in Malawi. Fused together, these theoretical perspectives underpin a political economy analysis (PEA) framework. The overarching goal of the PEA framework is to illuminate on how groups in a society compete for and use resources, rents, and power to advance their interests (Prowse and Grassin 2020). This entails systematically mapping all key actors in an issue area; identifying their interests and recognising their forms of power (political, economic, social, and ideological); understanding their relationships with each other; and appreciating the issues, narratives, and ideas that shape how and why they interact with each other. The underlying argument is that the distribution of organisational power is important for understanding the economic and political effects of institutions and policies. This implies that policymaking does not happen in neat and predictable step-by-step fashion, informed by problem free or neutral knowledge; it is a highly contested process (Khan 2017; Laws and Leftwich 2014; Keely and Scoones 2003).

With these political economy lenses, the paper addresses the following three substantive questions and three hypotheses, respectively, to understand the status of the groundnut value chain in Malawi:

- What are the underlying dynamics of social differentiation within the groundnut value chain?

- What is the impact of climate change on the productivity and profitability of the groundnut value chain?

- What is the impact of the COVID-19 pandemic on the agri-food systems in Malawi through the experiences of the groundnut value chain?

- If the country is landlocked, engagement in the value chain by national elites takes the form of acquiring land for crop production,

1 Most of the interviewees preferred anonymity in view of the sensitivity of the issues that were discussed about the groundnut value chain. For this reason, the interviewees are not explicitly identified, except in cases where matters directly linked to them are not deemed sensitive. The details of the interviews are provided in Annex 2. 
seeking to secure reliable market outlets and prices for their produce through manipulation of state policies, and/or orchestrating the availability of cheap inputs (e.g. fertilisers), equipment (e.g. tractors), and services that they can 'capture'.

- If production of the crop primarily takes place in sub-national regions with high population density (greater than 200 persons per km²); production and sale for market are both dominated by smallholder farmers, despite the interest of larger players in entering the value chain. Conversely, where production of the crop primarily takes place in sub-national regions with low to medium population density (less than 200 persons per km²); medium and perhaps also large-scale farms have expanded their production and marketing of the crop dramatically over the past decade.

- If traditional development partners have engaged actively with the value chain over the past decade: policy interventions have both been designed to stimulate commercialisation in some form or another and to facilitate the participation of smallholder farmers in the resulting commercialisation processes.

Social differentiation entails distinction between groups and individuals on the basis of biological and sociocultural factors, such as sex, age, class, or ethnicity, resulting in assignment of roles and status in society. In this paper, particular focus is paid to the gender dimension of social differentiation in the groundnut value chain, while recognising the role of intersectionality in social differentiation. Intersectionality focuses on understanding how aspects of a person's social and political identities combine to create different modes of discrimination and privilege. It is a prism for seeing the way in which various forms of inequality often operate together and exacerbate each other (Crenshaw 1989). It illustrates how people's social identities can overlap, creating compounded experiences of discrimination. The focus areas of this paper, among other aspects, are the barriers to entry and/or requirements for men and women to participate in the value chain; the differences in men's and women's ability to maintain or improve their position in the value chain; and the differences in men's and women's ability to access and control benefits from the value chain.
These are gender-based constraints because they are linked to particular laws or practices that are different for men and women (Rubin, Manfre and Nichol-Barret 2009).

The findings of this paper demonstrate that the groundnut value chain has huge potential to contribute to the transformation of Malawi's agriculture sector, especially among smallholder farmers. A viable groundnut value chain can serve as a leading source of income through both domestic and export trade, as demand on both fronts remain unmet. Although the groundnut value chain exudes this enormous potential, it does not receive adequate attention from the public sector in order to fully unleash its full potential in the country's agriculture portfolio. Instead, the groundnut value chain has been captured by a cartel of traders (local and foreign), technocrats, and politicians, who make supernormal profits through the thriving informal export trade, especially within the subregion. While legumes (mainly groundnuts, soya beans, and pigeon peas) have been designated as potential replacement crops for the fledgling tobacco sector, as a leading foreign exchange earner, in the National Export Strategy (NES) (2012-2018) (GoM 2012), this strategy has not been matched with government determination to facilitate its realisation. There is also a great deal of social differentiation within the groundnut value chain, shaped to a great extent by the broader processes of social differentiation in rural Malawi. This social differentiation demonstrates the impact of intersectional barriers on the livelihoods of women, poorer men, and youth. ${ }^{2}$ The mainstream narrative simply projects the groundnut value chain in Malawi as unviable because of limited productivity, due to the dominance of smallholder farmers in the value chain; the unattractiveness of the value chain to private sector investment, especially the groundnut seed system, which is key to improved productivity; and the inability of most producers, especially smallholder farmers, to limit aflatoxin to acceptable levels, particularly for regional export markets and beyond. Moreover, efforts to resuscitate and formalise the export trade of commodities, including legumes, through structured markets such as commodity exchange platforms, are fiercely resisted. Meanwhile, the informal export trade, particularly of groundnuts, continues to thrive and is not even disguised.

The remainder of the paper is organised as follows. Section II briefly sketches out the conceptual and

2 The Government of Malawi Youth Policy (2013) officially defines youth as all persons from age 10 to 35 years, regardless of their sex, race, education, culture, economic, marital and physical status. The policy observes that the definition of youth has continuously changed in response to political, economic, and social perspectives. However, communities in both rural and urban areas, tend to define youth to include even those that are beyond 35-years-old, as long as they are not married, although they may be living independent lives (see, for example, Chinsinga and Chasukwa, 2012). 
empirical underpinnings of the paper. The first part discusses the theoretical scaffolds of the paper, rooted in the PEA tradition that fuses together ideas about political settlement, rent, and policymaking processes. The second part provides a quick review of Malawi's political settlement, especially in terms of how it has evolved following the transition to democracy in May 1994, with particular reference to its implications for rent management and policymaking processes. Section III maps out the groundnut value chain in terms of the major actors, its performance from contemporary and historical perspectives, and key policy drivers for its successes and failures. Section IV focuses on the apparent resurgence of the groundnut value chain, following its collapse towards the end of the 1980s. It addresses the factors driving the resurgence, including policy initiatives and efforts, as well as obstacles, such as climate change. Section $V$ discusses the apparent strategic neglect and capture of the value chain by focusing on the thriving informal export trade, which generates millions of US dollars, while efforts to formalise trade are fiercely resisted. Section VI turns to the underlying dynamics of social differentiation within the groundnut value chain, while paying attention to how forces in this context interact with forces in the wider context to produce outcomes that tend to marginalise women on several fronts. Section VII explores how the COVID-19 pandemic has affected the country's agrifood system through the lens of the groundnut value chain. Section VIII offers some concluding remarks and reflections. 


\subsection{Political settlement, rents and policymaking}

Political settlement, rents, and policymaking as conceptual scaffolds are rooted in the PEA tradition, which is broadly concerned with the dynamic interactions between structures, institutions, and actors, to understand how decisions are made in countries, societies, and sectors (Laws and Leftwich 2014). There are competing definitions of political settlement, but regardless of the definition used, it helps shed light on issues of rent management and policymaking processes in a country, society, or even sector. For the purposes of this paper, political settlement is defined as the balance or distribution of power between contending social groups and classes on which any state is based. Defining political settlement in this way helps to focus attention on intra-elite contention and bargaining; contention and bargaining between elites and non-elites; and contention and bargaining between those who occupy the state and society more broadly (Di John and Putzel 2009). This means that political settlement allows for a more detailed understanding of how the interests, ideas, and relations of power among leaders, elites, and coalitions can assist or obstruct the process of change.

The distribution of power that a political settlement underpins, entails the likelihood of particular organisations holding out in contests seeking to influence institutional outcomes (Khan 2017). Powerful organisations can outclass competitors in contests of power and authority because they can either deploy more resources to influence governments or other organisations, inflict greater costs on competitors, or hold out for longer because they can absorb more damage until others give in. The holding power of organisations is not just based on economic capabilities, or on whether they include elites, but also on their organisational capabilities to mobilise and their skills in identifying and rewarding the right people through formal or informal networks. This invariably draws attention to the fact that political settlement does not only refer to the formal architecture of politics, but also the web of informal rules, shared understandings, and rooted habits that are at the heart of every political system (OECD 2011). Consequently, groups that may appear powerful in terms of their formal and economic positions in society may not be able to actually enforce compliance with the formal and informal institutions they desire, leading to a much more complex relationship between institutions and paths of political and economic change (Gray 2019).

The contestations between and among groups in countries, societies, or sectors produce winners and losers. The tendency for winners is to push for the maintenance of the status quo, whereas losers push for changes to the status quo so that they can become winners should their desired social, economic, or political institutional arrangement be realised. This is inevitable because processes of institutional change are never neutral, they distribute advantages to some and disadvantages to others such that they mobilise bias in some way or another. The processes of institutional change are thus often heavily contested by diverse interests with different forms and degrees of power, influence, and authority. This creates winners and losers, which have a bearing on social differentiation processes in a country, society, or even in a sector. While seminal work on social differentiation leaned heavily toward the functionalist perspective, emphasising that it is imperative for the preservation of the social system, there is increasing recognition that it also creates the potential for structured inequalities built into the larger social system, giving unequal access and opportunities to different groups. It is, therefore, construed as a double-edged sword. While from a functionalist perspective, structured inequality can be seen as an efficient way to organise society, it can also lead to conflict and social problems, including poverty.

Building on two competing contemporary perspectives of social differentiation, Dancer and Hossain (2018) argue that the analysis of social differentiation draws attention to the interconnection between individual agency, social structures, and wider political developments. According to Berry (1993), social differentiation arises out of local social relations that are fluid and dynamic, underpinned by struggles over resources, while Hall, Scoones and Tsikata (2017) attribute social differentiation to situations such as commoditisation and economic liberalisation, which 
produce and deepen inequality and exclusion for certain groups. Dancer and Hossain (2018) emphasise the importance of intersectionality in understanding the underlying dynamics of social differentiation in a country, society, or even a sector. Intersectionality seeks to understand the complexity of interactions across multiple forms of social categories, including gender, age, class, religion, and ethnicity, in shaping social structures and matrices of inequality and oppression. The processes of social differentiation have consequential impacts for the empowerment of people in society, especially women and girls. Dancer and Hossain (2018) define empowerment as a process of change through which groups that have been denied the ability to make strategic life choices come to acquire that ability.

\subsection{A brief overview of Malawi's political settlement}

Examining Malawi's political settlement and its underlying rent management and policymaking processes is very important because the primary interests of the governing elite are paramount in driving, shaping, and influencing development and programme and/or project implementation outcomes (Chinsinga 2018). The dominant tendency for elites is to frame development interventions, as well as their implementation, in a manner that would retain them in power. This takes full cognizance of the fact that the underlying political settlement is never static. Changes in the political landscape often alter the underlying interests of political elites, as well as the networks and coalitions behind those interests, with potentially different development and/or project implementation outcomes. According to Prowse and Grassin (2020), vested interests within elite circles swirl around and soak into governance processes, since they always want to ensure that their interests are served.

Malawi's political settlement has experienced significant change, following the transition from a oneparty dictatorship to a multi-party democracy in May 1994, largely in terms of rent management. However, its underlying operative dynamics have remained squarely intact (Prowse and Grassin 2020; Cammack 2010). From an authoritarian developmental patrimonialism with centralised and systematic rent management, underpinned by policy driving patronage, Malawi has evolved into a competitive clientelist regime, where patronage drives policy and is underpinned by rampant fraud, corruption, nepotism, and sheer opportunism with a decentralised rent management system. Prowse and Grassin (2020) make an interesting observation in this regard. They argue that patrimonialism contributes to or constrains fundamental structural transformation, depending on whether the control of rents is centralised and long-term or dispersed and for instant gratification. The fairly impressive development achieved during the one-party dictatorship between July 1964 and May 1994 is attributed to three main factors. These are: 1) the distribution of rents and assets to actors who made use of them productively; 2) an insulated professional cadre of civil service technocrats; and 3) the clear planning of development priorities and effective implementation.

One of the major persistent challenges that Malawi grapples with is its failure to diversify its agricultural portfolio. Malawi remains hooked to maize as its staple food, despite efforts to diversify over the past five decades (Scott and Chinsinga 2018). While the subsidy support programmes implemented since the late 1990s have attempted to facilitate diversification of the country's crop portfolio, these efforts have not been very successful. A very good example in this regard is the Farm Input Subsidy Programme (FISP) that was implemented between 2005 and 2020. Even though FISP was designed to cater for crop diversification and efforts were continually made to ensure that this was achieved, it was implemented in a blanket fashion, despite the poor performance of maize in some areas. Not only were legumes not regularly included in the FISP package to facilitate diversification, farmers in areas where maize does not do well could have been supplied with alternative crops, such as sweet potatoes or cassava. This is not surprising because policies concerning maize and its status as the country's staple lie at the heart of Malawi's political economy. The emotive issue of maize security underlies policies that are reactive rather than proactive and riddled with opportunities for rent seeking (World Bank 2018). As a result, maize is subject to ad hoc maize export bans, driven by the political imperative of food insecurity, even though this disincentivises investments in commercial farming and agricultural growth (Scott and Chinsinga 2018).

These political settlement dynamics are anchored by the enduring one-party political culture, which has changed and adapted to multi-partyism and elections, without losing its force (Cammack, Kelsall and Booth 2018; Chinsinga 2018). This political culture is characterised by the prevalence of patronage, clientelism, opportunism, and corruption; the centralised authoritarian tendency of the executive; the relative weakness of the citizenry and civil society visà-vis the state; the narrowness of the public sphere; 
the deference to hierarchy; and gender discrimination. ${ }^{3}$ Consequently, rather than basing their campaigns on ideologies or issues, most politicians have promised goods or have appealed to ethnic, regional, or religious identity to gain political support. This has ended up creating powerful Presidents because political parties in the country are built around a 'big-man' or a 'big woman' with members drawn together because of their shared loyalty to him, rather than a unifying ideology. The resulting political configuration makes it easier for politicians to advance their personal agendas because there is little clarity or widely shared understanding of what is in the public interest. Politicians' personal agendas can therefore be sold to the nation as being in the public interest. According to Prowse and Grassin (2020), there is little evidence that groups in Malawian society based on class have managed to compete for resources, rents, and power. The battle of ideas within Malawi often appears to be secondary to material concerns.

It is within this context that the political economy of the groundnut value chain is analysed. The World Bank (2018), sums up the context perfectly: Malawi's policy arena is shaped by its unique combination of structural conditions, historical legacies, and the evolution of its political settlement. This political settlement is characterised by an elite bargain that allows competition among a small elite while providing stable benefits to them; fragmentation along identity lines; high donor dependence; and a limited social contract based on food security, and maize, in particular (Cammack, Kelsall and Booth 2018). These characteristics have contributed to a stable, but low-level equilibrium, trapping the country in a cycle of crises, followed by reactive responses, rather than facilitating the deeper commitment needed to break out of the cycle. Where reform efforts have had traction, elite incentives have been aligned due to either being in a vulnerable political position and therefore the need to shore up support through performance, or because of the need to address a threatening economic crisis and reinstate donor aid.

There are, however, some prospects for fundamental change in the configuration of the country's political settlement, following the Fresh Presidential Elections (FPEs) on June 23 2020, which ushered in a new coalition government under the leadership of $\mathrm{Dr}$ Lazarus Chakwera (Chinsinga and Mihowa 2020). The FPEs were held under the majoritarian electoral system for the first time since the transition to multi-party democracy in May 1994, following the courts' direction as part of the remedies to the nullification of the disputed elections on 21 May 2019. As a result of the courts' reinterpretation of Section 80 (2) of the Constitution, the President is now required to be elected by 50 per cent plus one of voters at the polls. This dramatically changes the calculus for aspiring candidates to become President of the country. They would have to invest in broad based national coalitions, which may make the provision of public goods an attractive option for appealing to potential voters and even as a strategy for maintaining power. The new government ascended to power on a platform of creating a new Malawi that provides access to public goods and resources on an equitable basis. This is, inter alia, reflected in the farreaching public sector reforms that the government is implementing, but it is too early to judge their potential impact.

3 Corruption is defined as a form of dishonesty or criminal offence undertaken by a person or organisation entrusted with a position of authority to acquire illicit benefit or abuse of power for one's private gain, while clientelism is a practice of allocating private goods, such as jobs or other opportunities, by a patron to his or her clients with an expected return of favours that reinforces patronage. This implies that clientelism is the selective provision of benefits and resources to limited segments of the population. Patronage, therefore, refers to the control or power to make or grant favours to followers or supporters on the basis of largely political considerations (see, for example, de Sardan 1999). 


\section{THE GROUNDNUT VALUE CHAIN IN MALAWI}

\subsection{Understanding agricultural value chains}

There are different types of value chain, which include a wide range of activities. Prowse and Grassin (2020), for example, distinguish five different value chains, depending on how power is exerted in the chain. The way in which power is exercised in a value chain is dependent on the complexity of transactions; the ability of actors to access and interpret information; and supplier capability. According to Prowse and Grassin (2020), the five different types of value chain include global, modular, relational, captive, and hierarchical; each with different governance implications. There are, however, some key elements of agricultural value chains. These may include the following: development and dissemination of plant and animal genetic material, input supply, farmer organisation, farm production, post-harvest handling, the provision of production techniques, handling and grading criteria and facilities, cooling and packaging technologies, local postharvest processing, industrial processing, storage, transport, and feedback from markets (Norton 2014). A value chain approach to agricultural development helps to identify weak points in the chain and actions to remedy them.

The major distinctive feature of agriculture in developing countries is that it is often characterised by dual value chains operating in parallel for the same product: one formal and the other informal. Norton (2014) observes that smallholders are frequently involved in informal chains that deliver products to local middlemen and then to small local stores. Formal value chains can deliver the same product, usually in better or more uniform quality, from large farms or more organised groups of small farmers to more commercial wholesalers and from there to supermarkets or exporters. This duality has been accentuated by the explosive growth of supermarkets in developing countries. It can limit many small producers to markets characterised by low quality products and low returns. The issue therefore becomes how to find ways to integrate small producers into more modern value chains, both domestically and export oriented.

\subsection{The importance of groundnuts}

Groundnuts are widely acknowledged as the most important legume crop in Malawi, both in terms of production area and volume (Itai 2020; Mgalamadzi 2018). It is predominantly grown by about 100,000 smallholder farmers in the country. Smallholder farmers account for as much as 93 per cent of total groundnut production in Malawi, while the remainder is produced by estates. While groundnuts can and do generally well across the country, the central region dominates in the production of groundnuts, particularly in the districts of Dedza, Dowa, Kasungu, Lilongwe, Mchinji, Ntchisi, and Salima (NASFAM 2013; Simtowe et al. 2009).

Groundnuts play a key role in the country's national and household economies. As one of the key staples, groundnuts provide a vital source of nutrition, especially for rural households (Inclusive Business Action Network 2020). It is a very important component of households' diet through its provision of valuable protein, edible oil, fats, energy, minerals, and vitamins. It plays a key role in farming, especially for resource constrained households, who cannot afford fertiliser. Groundnuts can be used for making livestock feed, which enhances livestock productivity, thereby enhancing the resilience of households against poverty. Last but not least, groundnuts are one of the country's sources of foreign exchange, which contributes to the growth and resilience of the economy. At the household level, it is estimated that groundnuts contribute about 25 per cent of total income (Cook et al. 2014; NASFAM 2013; Simtowe et al. 2009).

\subsection{The status of the groundinut value chain}

The groundnut value chain in Malawi has evolved significantly since the turn of the 1990s. There is, however, a single major policy event that accounts for most of the changes that have taken place and continue to take place in the groundnut value chain. The introduction of SAPs in the agricultural sector at the instigation of the World Bank and the International Monetary Fund (IMF) prompted changes, which, as 
Figure 3.1: The groundnut value chain in Malawi

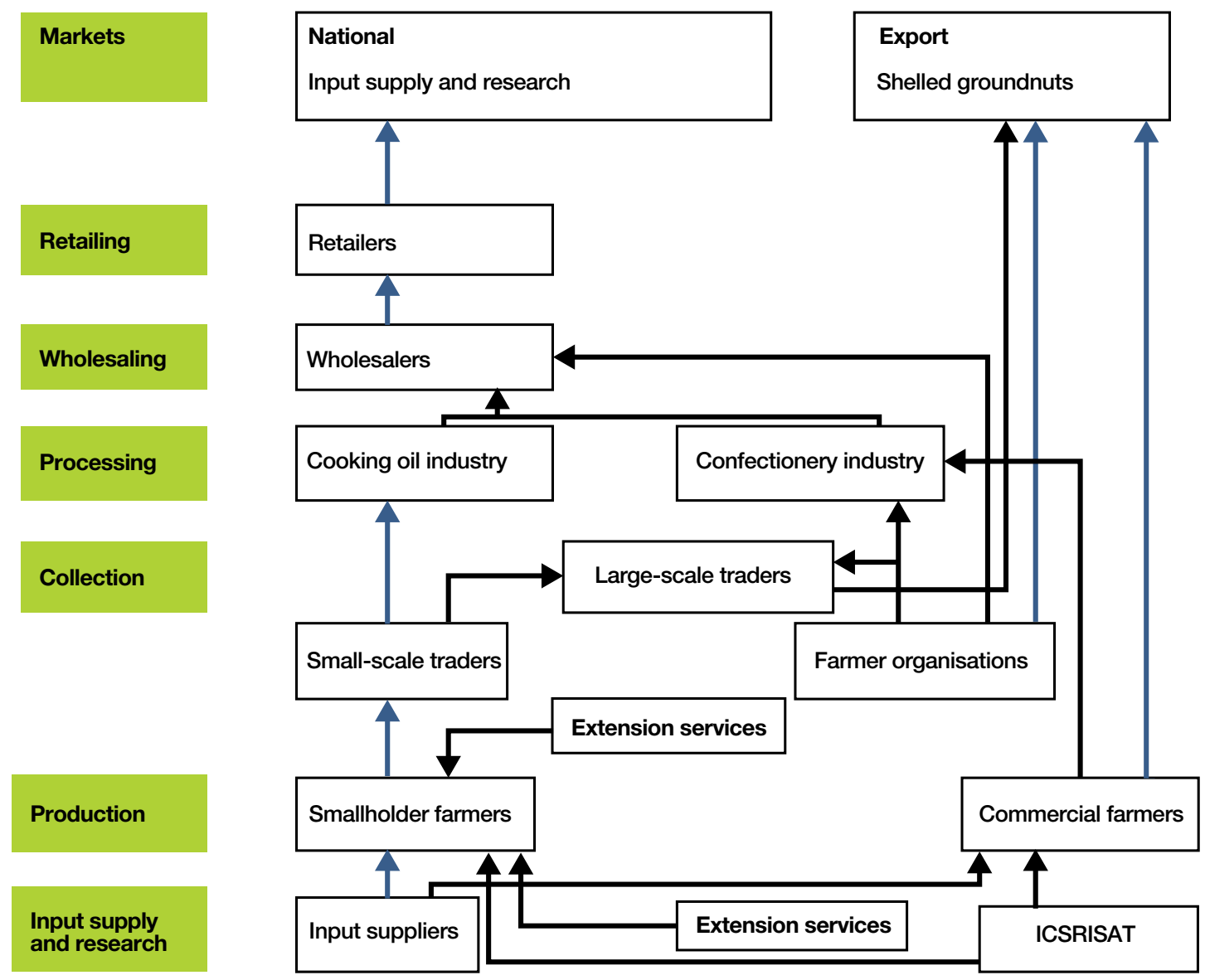

Source: Adapted from Farm Radio International (2013)

further elaborated below, have altered the groundnut value chain. In addition, some of the changes that have occurred are in response to the challenges that arose as a result of the implementation of the SAP policy prescriptions. Figure 3.1 represents the status quo of the groundnut value chain in Malawi since the introduction of SAPs.

Table 3.1 describes the roles of the various players in the groundnut value chain. This helps to set the stage for understanding how the development of the groundnut value chain has been influenced by the implementation of and response to the challenges arising out of the SAP policy prescriptions (Farm Radio International 2013; NASFAM 2013; Simtowe et al. 2009).

\subsubsection{Production and export trends in the} groundnut value chain

Although these stakeholders do not map out exactly to those in Figure 3.1, Table 3.1 provides a clear picture of the key stakeholders and their roles in the groundnut value chain. The interactions, engagements, and contestations between and among these stakeholders

are key to understanding the groundnut value chain, both from a contemporary and historical perspective.

\subsubsection{Production and export trends in the groundnut value chain}

Despite its apparent importance in the country's economy, the performance of the groundnut value chain has been somewhat mixed. As Figure 3.2 demonstrates, production has fluctuated wildly, while exports almost completely collapsed, especially at the turn of the 1990s. However, there are some promising signs of recovery in recent years.

There have been several commentaries on the trends in production and export of groundnuts in Malawi. Matita (2018) observes that groundnut production was at its peak in the 1970s, when it constituted the third largest export crop. As shown in Figure 3.2, the production of groundnuts collapsed at the turn of the 1990s and, at the same time, the export market almost disappeared. There has been some recovery, especially since the late 1990s. Overall, however, groundnut production has not increased fast enough to recover to the pre- 
Table 3.1: Stakeholders in the groundnut value chain

\begin{tabular}{|c|c|}
\hline Stakeholder & Role \\
\hline $\begin{array}{l}\text { Smallholder } \\
\text { farmers }\end{array}$ & $\begin{array}{l}\text { - } \quad \text { Constitute the biggest and most important group in the chain. } \\
\text { - } \quad \text { Comprise of women (in male headed households and female headed households), men, and youth, who are } \\
\text { either rural or urban based, and both better off and poor households. } \\
\text { - Major producers of groundnuts, but since they are not often well organised their participation in the value chain } \\
\text { is limited. } \\
\text { - Organisations such as the National Association of Smallholder Farmers of Malawi (NASFAM) and One Village } \\
\text { One Product work with smallholder farmers to organise them into associations or cooperatives. }\end{array}$ \\
\hline Seed companies & $\begin{array}{l}\text { - } \quad \text { Examples include SeedCo Malawi, Demeter, Pannar, Farmers World, NASFAM etc. } \\
\text { - Engaged in seed multiplication (mostly urban based weekend farmers) from both global and national research } \\
\text { - } \quad \text { Subcontres. } \\
\text { - } \quad \text { Availability of seed, especially to most rural farmers, is a very big challenge. }\end{array}$ \\
\hline Agro-dealers & $\begin{array}{l}\text { - } \quad \text { Serving as a source of inputs to farmers including groundnut seed. } \\
\text { - Filling the gap left by the Agricultural Development and Marketing Corporation (ADMARC), especially in rural } \\
\text { areas. } \\
\text { - Most agro-dealers, however, prefer operating in areas with easy access and good infrastructural networks, } \\
\text { leaving out the remotest areas of the country. }\end{array}$ \\
\hline $\begin{array}{l}\text { Association of } \\
\text { Smallholder Seed } \\
\text { Multipliers Action } \\
\text { Group (ASSMAG) }\end{array}$ & $\begin{array}{l}\text { - } \quad \text { Produces or multiplies groundnut seed on contracts for seed companies. } \\
\text { - } \quad \text { Requires membership for all participants, which excludes the poorest smallholder farmers. }\end{array}$ \\
\hline $\begin{array}{l}\text { Intermediate } \\
\text { buyers and small } \\
\text { traders }\end{array}$ & $\begin{array}{l}\text { - } \quad \text { Driven by the desire to make money before smallholder farmers take their groundnuts to big markets or buyers } \\
\text { (includes men and women mostly from urban areas). } \\
\text { - } \quad \text { Target farmers at the beginning of the harvesting season when they are desperate for quick cash. } \\
\text { - } \quad \text { First customers of the smallholder farmers, who then sell to larger traders at a slightly higher price. } \\
\text { - } \quad \text { Intermediate buyers set prices for the vendors and in order to maximise their gains, vendors deflate prices so } \\
\text { - } \quad \text { as to make a profit. }\end{array}$ \\
\hline $\begin{array}{l}\text { Processors and } \\
\text { exporters }\end{array}$ & $\begin{array}{l}\text { - Examples include organisations and companies such as NASFAM, Mulli Brothers Limited, Tambala Food } \\
\text { Products, Export and Trading Company, Rab Processors and some individuals from both within and outside } \\
\text { the country. } \\
\text { - } \quad \text { Buy groundnuts from traders, add value, and export. } \\
\text { - Often fail to meet export demands due to low production and high levels of aflatoxin, which also affects the } \\
\text { production of oil and other products. }\end{array}$ \\
\hline Consumers & $\begin{array}{l}\text { - Consume groundnuts and groundnut-based confectionaries, which, inter alia, include peanut butter and nuts } \\
\text { that are available in retail supermarkets and other grocery stores. } \\
\text { - Some of the shelled groundnuts are exported to regional markets, including Kenya, South Africa, and } \\
\text { Tanzania. } \\
\text { - A consumer association exists, but focuses on matters affecting mostly urban dwellers, for example, water, } \\
\text { electricity, housing, and quality of products in supermarkets. }\end{array}$ \\
\hline $\begin{array}{l}\text { Research } \\
\text { institutions and } \\
\text { academia }\end{array}$ & $\begin{array}{l}\text { - Key players include the Department of Agriculture Research, Bunda College of Agriculture and the International } \\
\text { - } \quad \text { Interested mainly in improving production and productivity through research and training. } \\
\text { - } \quad \text { Conduct and set the policy research and training agenda for quality improvement. } \\
\text { - Grapple with limited human and financial resources to conduct responsive research and training based on the } \\
\text { needs of smallholder farmers. }\end{array}$ \\
\hline
\end{tabular}




\begin{tabular}{|c|c|}
\hline $\begin{array}{l}\text { Civil society } \\
\text { organisations } \\
\text { (CSOs)/Non- } \\
\text { governmental } \\
\text { organisations } \\
\text { (NGOs) }\end{array}$ & $\begin{array}{l}\text { - Interested in ensuring that smallholder farmers are effectively participating in the groundnut value chain. } \\
\text { - } \quad \text { Keen on improving smallholder farmers' livelihoods by diversifying their crops, increasing their household } \\
\text { income base, and mitigating the impact of climate change. } \\
\text { - } \quad \text { Make seed available to farmers at affordable prices through various seed schemes. } \\
\text { Provide their own extension services and collaborate with government extension staff to provide extension } \\
\text { services to farmers. }\end{array}$ \\
\hline $\begin{array}{l}\text { Micro-finance } \\
\text { institutions }\end{array}$ & $\begin{array}{l}\text { - Examples include Concern Universal Microfinance Operations, Foundation for International Community } \\
\text { - } \text { Assistance, Malawi Union of Savings Credit Cooperatives, Micro-loan Finance etc. } \\
\text { ratend credit to farmers, but most farmers have not benefited from them because they charge high interest } \\
\text { - Village savings and loans groups provide modest and pro-poor loans to smallholder farmers, but not much is } \\
\text { known about them. }\end{array}$ \\
\hline $\begin{array}{l}\text { Middlemen/ } \\
\text { vendors }\end{array}$ & $\begin{array}{l}\text { - Comprise of both men and women, but predominantly men, and based either in urban areas or in trading } \\
\text { - Sentres. } \\
\text { - } \quad \text { Although they create a market for desperate smallholder farmers, they often buy groundnuts at depressed } \\
\text { prices to extend their profit margins. } \\
\text { - Serve as the only marketing outlet for farmers especially in remote areas. }\end{array}$ \\
\hline Government & $\begin{array}{l}\text { - Set policies and provide the overall framework for the value chain players and actors to operate. } \\
\text { - The most relevant ministries include the Ministry of Agriculture, the Ministry of Trade, the Ministry of Industry, } \\
\text { the Ministry of Gender, and the Ministry of Local Government. } \\
\text { - Run programmes and projects such as FISP, now the Affordable Input Programme, and Rural Livelihood and } \\
\text { Economic Enhancement Programme, which provide farmers with access to groundnut seed. } \\
\text { - Some of the projects focus on groundnut value chain development through productivity enhancement and } \\
\text { commercialisation. }\end{array}$ \\
\hline Donors & $\begin{array}{l}\text { - Donors include USAID, Norway, and Irish Aid. These donors have mostly supported the development of the } \\
\text { groundnut seed system, particularly in the development of breeders' and basic seed. } \\
\text { - Supported the development of several groundnut varieties, but most of these are yet to be released to farmers } \\
\text { due to funding constraints. } \\
\text { - Work through ICRISAT and the Department of Agricultural Services of the Ministry of Agriculture. }\end{array}$ \\
\hline
\end{tabular}

Source: Authors' own (2020)

Figure 3.2: Groundnut production and export trends in Malawi (1961-2018)

Groundnuts Production and Exports (1961-2018)

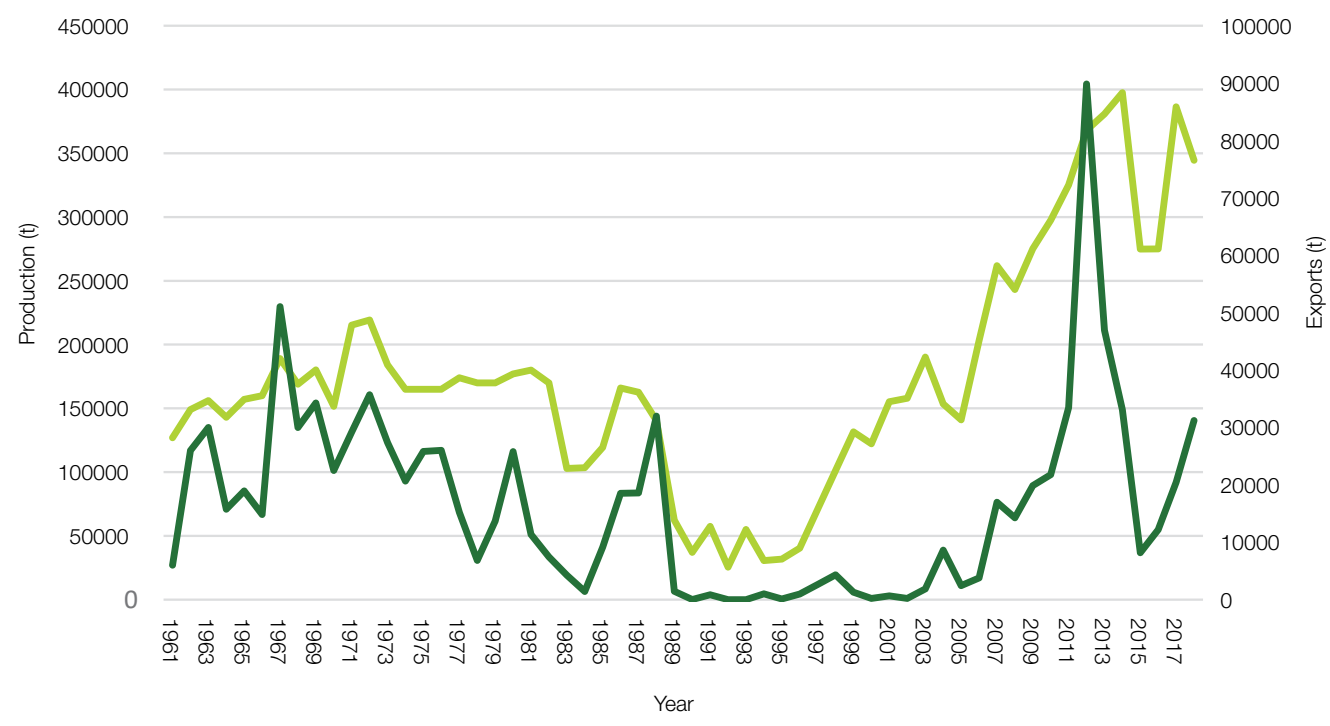

Source: Computed from FAOSTAT (1961-2018) 
1990 levels. UNIDO (2012), for instance, estimates that between 1961 and 2005, the amount of land under groundnut cultivation in Malawi increased from 159,000 ha to almost 267,000ha, representing an average annual growth rate of 3.4 per cent. NASFAM (2013) emphasises that the growth has been quite variable with only 50,000ha cultivated in 1990.

The dramatic decline in groundnut production in 1990 is attributed to the collapse of exports in 1989. Malawi's groundnut export fell from 30t in 1988 to zero in 1989 due to the detection of high aflatoxin levels when the groundnuts landed in the United Kingdom (UK) (UNIDO 2012). As can be seen from Figure 3.2, groundnut exports remained low after 1990, but appear to make a recovery in 2004 when exports increased to 8.6 per cent. The performance of the groundnut value chain has never recovered to the pre-1990 levels, except in 2011, when groundnut exports shot to about 90,000t. Similarly to production levels, the export performance has been quite variable. For example, exports fell to $2.4 \mathrm{t}$ in 2005 and picked up to 3.8t in 2006. Exports then increased to $16.9 \mathrm{t}$ in 2007 , decreased to $14.3 \mathrm{t}$ in 2008, and increased to 19.9t in 2009.

Simtowe et al. (2009) observe that Malawi was ranked as the thirteenth largest producer of groundnuts in Africa for the period 2001-2006. They estimated that, during this period, Malawi produced an average of 157,000 t of groundnuts per year, which accounted for 2 per cent of total production in Africa. While production of groundnuts appears to have recovered, exports remain very low. The land cultivated for groundnut production has steadily increased since 1990, such that, by 2006 it had again reached the 1980 hectarage. However, groundnut exports remain below its peak in the 1980s, at about 50,000t per annum. According to Farm Radio International (2013), about 60 per cent of all groundnuts produced in Malawi are consumed at household level or sold in local markets. The other 40 per cent go to processors, exporters, wholesalers, and retail markets. Of this, 25 per cent are sold in Malawi and exported to countries such as Kenya, South Africa, Tanzania and the UK. The remainder is sold through informal export trade.

The key question becomes: what explains this fluctuating performance of the groundnut value chain in Malawi for the past four decades, or so? The rest of this section therefore discusses some of the factors that shed light on the production and export performance of the groundnut value chain in Malawi.

\subsubsection{The collapse of ADMARC}

The impact of SAPs is probably felt the most through the fate of ADMARC, which prior to the roll out of SAPS, provided production and export support infrastructure for groundnuts (Scott and Chinsinga 2018). As a crop marketing board, ADMARC provided farmers with ready markets and guaranteed prices for their produce. In addition, ADMARC provided farmers with required inputs, such as quality seed and pesticides, and was supported by a robust Ministry of Agriculture extension system, which used to provide technical advice and support to smallholder farmers (NASFAM 2013). The adoption of SAPs weakened the capacity of ADMARC to buy and export groundnuts, as well as provide requisite extension services.

The collapse of ADMARC has had several impacts on the performance of the groundnut value chain in terms of production and export. As elaborated further below, the streamlining of ADMARC's network has created considerable marketing challenges for groundnuts. Most smallholder farmers now rely on vendors to sell their groundnuts, usually at exploitative prices (Matita 2018; Mgalamadzi 2018). Agro-dealers, who have emerged to fill the vacuum left by the rollback of ADMARC's network, prefer to operate in areas with easy access and good infrastructural networks, leaving out the remotest areas of the country (NASFAM 2013; Chinsinga 2011). While marketing boards generally have a bad reputation across the continent, there is palpable nostalgia for ADMARC because the alternative marketing outlets have proven even worse. Most private traders limit their services to trading centres, which are along main roads, yet Malawi is predominantly rural, making it difficult for farmers to sell their produce. ADMARC had a network of markets across rural areas; their markets opened on time and offered better and stable prices. As a result, there are always calls by farmers for ADMARC to return to its pre-SAP modus operandi.

Farmers find it very difficult to access improved seed, which is vital to increasing productivity of groundnuts. With ADMARC out of the scene, or playing a much more diminished role, farmers have to find alternative means to get quality improved seed (Nyondo, Nankhuni and Me-ksope 2018). Most farmers 'cannot afford improved quality groundnut seed because it is very expensive; it costs MK1,500 per $\mathrm{kg}$ which is equivalent to US\$2, yet a hectare requires about $90 \mathrm{~kg}$ of seed, and besides, groundnuts have low seed multiplication ratio'. $A$ comparison with pigeon peas is quite revealing. The seed rate of groundnuts is at least 10 times more than that of pigeon peas, while the multiplication ratio is

4 Interview with the Acting Chief Executive Officer of ADMARC, 21 July 2020 
at least four times lower. While farmers require 80$100 \mathrm{~kg}$ of seed per ha for groundnuts, they require only $10 \mathrm{~kg} / \mathrm{ha}$ for pigeon peas (Nyondo, Nankhuni and Me-ksope 2018). The majority of smallholder farmers are unable to economically access adequate quantities of certified groundnut seed and the private sector has found it difficult to develop a commercially viable seed market for groundnuts.

Simtowe, Longwe-Ngwira and Siambi (2012) estimate that only 40 per cent of the total harvested groundnut area was covered by improved groundnut varieties. This partly explains the failure of groundnut farmers to realise the full yield potential for the groundnut varieties that they cultivate. For instance, Farm Radio International (2013) estimate that farmers get average yields of $1,000 \mathrm{~kg} / \mathrm{ha}$ (for CG7 and Nsinjiro varieties) and $600 \mathrm{~kg} / \mathrm{ha}$ for the Chalimbana variety. Yet there is potential for much larger yields through the use of improved seed coupled with good management practices. The maximum potential yield for $\mathrm{CG} 7$ is 2,500 kg/ha, 2,000 kg/ha for Nsinjiro, and 1,500 kg/ha for Chalimbana. One of the interviewees argued that, 'we cannot realise these yield potentials because our farmers cannot access improved groundnut seed, but even more critically, we are still deeply wedded to backward technology, for example, planting groundnuts on ridges'. ${ }^{5}$ Improved quality groundnut seed is simply not available in the right quantities to meet the farmers' demand. Subsidy programmes such as FISP have not been able to mobilise adequate seed for distribution to farmers, 'simply because the seed is not there and as such farmers simply resort to using recycled seed'. ${ }^{6}$ This assertion is reinforced by Simtowe, Longwe-Ngwira, and Siambi (2012), who assert that there is simply an absence of a stable and commercially viable groundnut seed market, hence farmers recycle grain and use it as seed.

NGOs have attempted to address the limited availability of quality groundnut seed. These efforts have included providing farmers with quality groundnut seed for multiplication. When farmers receive say $50 \mathrm{~kg}$ of groundnut seed, they pay back the NGOs $100 \mathrm{~kg}$ of groundnuts, which are shared with other farmers for at least three years before the seed loses its production vigour (Itai 2020; NASFAM 2013). The impact of these initiatives has been very limited and because of their project oriented nature, which means that farmers continue to use the seed for more than three years. Using the seed for more than three years weakens its productive vigour, which translates into low yields. Seed companies are reluctant to engage in the groundnut seed system since farmers can recycle seed without experiencing significant yield reductions for at least three years. Seed companies, especially international ones, find the groundnut seed system less attractive for massive investment. These companies focus disproportionately on the production and marketing of hybrid maize seed due to its high excludability and, hence, high profitability (Simtowe, LongweNgwira and Siambi 2012).

There is an opportunity for local seed companies to drive the development of the groundnut seed system, but there is limited public and private sector investment to spur its growth and development. Simtowe, Longwe-Ngwira, and Siambi (2012) observe that the government has not really prioritised the groundnut value chain, in terms of research and development aimed at enhancing the transformation of the groundnut sector in Malawi. Compared to other crops, such as maize and tobacco, the public sector investment in groundnut research and development initiatives has been quite negligible. In fact, nearly all research and development initiatives in the groundnut sector have been driven almost exclusively by donors through CGIAR centres, notably ICRISAT.

USAID has been the major donor driving research and development activities in the groundnut sector. USAID's support to research and development efforts for the groundnut sector dates back to 2008 and 'coincided with the country's efforts to diversify its export portfolio away from tobacco within the framework of the FISP'? The main goal of this support was to make adequate groundnut seed available to farmers to facilitate trade in groundnuts as a meaningful alternative to tobacco exports. Since 2015, Irish Aid has joined USAID to support research and development activities in the groundnut sector with 'particular focus on enabling farmers to get access to the improved seed that comes through the research and development activities at ICRISAT'.8 It is now estimated that the system is able to make as much as 30,000 t of groundnut seed available to the farming community.

Through this support, ICRISAT has produced several varieties of groundnuts since 2008. While some of these varieties have been released to farmers, many

5 lbid.

6 Interview with a former NASFAM official, 28 July 2020

7 Interview with the Country Director of ICRISAT, 27 October 2019

8 Interview with the Programme Manager of ICRISAT, 27 October 2019 
more are yet to be released. Those that have been released to farmers include Nsinjiro and Kakoma, and those yet to be released include Baka, modelled on South Africa's Natal Common, CG8, CG9, CG10, CG11, CG12, CG13, and CG14. While Nsinjiro and Kakoma are highly productive, they have challenges that make them less attractive to farmers. Nsinjiro has hard pods that make shelling difficult, while Kakoma is highly susceptible to rosette disease. Moreover, these varieties have struggled to break into the export market, 'which... [encourages] farmers to continue producing Chalimbana and CG7'.9 This is despite the fact that these varieties 'are not very productive, and the huge kernels for Chalimbana and high oil content (48-50 per cent) of CG7, make them less attractive for exports'.10 The major constraint, however, to making the improved seed varieties available to farmers is the lack of funding to facilitate the multiplication of these new varieties on a scale adequate to facilitate meaningful cultivation: 'we have developed these promising varieties, but they are yet to be released to farmers because we lack funding for the last mile for these varieties to reach farmers'.11 According to UNIDO (2012), ICRISAT has prioritised the provision of breeder and basic seed for groundnuts. It is estimated that ICRISAT produced 146t of basic seed and 25t of breeder seed between 1999 and 2006, which partly accounted for the recovery in both production and export performance of the groundnuts, as depicted in Figure 3.2.

\subsubsection{Deficient capacity to control aflatoxin levels}

The collapse of Malawi's groundnut exports, especially to Europe at the turn of the 1990s, is attributed to the failure to meet stringent quality measures imposed by the European Union (EU) to counter aflatoxin contamination (Nyondo, Nankhuni and Me-ksope 2018; Simtowe et al. 2009). Aflatoxin is produced by a fungus that grows on crops as a result of poor preand post-harvest practices. Inclusive Business Action Network (2020) estimates that trade losses attributed to aflatoxin contamination are US\$1.2 billion globally and US\$450 million in Africa.

Aflatoxin has become an issue in the local and export trade of groundnut because it is a health hazard. According to Farm Radio International (2013), groundnuts contaminated with aflatoxin are poisonous to people, causing liver cancer and stunting in young children. The EU, which was a major export destination for Malawi's groundnuts, set a maximum tolerable limit

9 lbid.

$10 \mathrm{lbid}$.

11 Interview with the Country Director of ICRISAT, 27 October 2019 of aflatoxin contamination of 4 parts per billion (ppb). The EU discontinued importing groundnuts from Malawi at the turn of the 1990s when assessments indicated that aflatoxin levels in Malawi's groundnuts exceeded 20ppb (Simtowe et al. 2009). With these high levels of aflatoxin contamination, Malawi is paying a huge health cost. Studies show that since 2000, 6,344 deaths annually can be attributed to aflatoxin induced liver cancer. These deaths are estimated to cost Malawi's economy between US\$25 million and US\$1.3 billion annually (excluding costs associated with lost export markets) (Nyondo, Nankhuni and Meksope 2018).

The worsening levels of aflatoxin in Malawi groundnuts coincided with the diminished role of ADMARC in the groundnut export trade, following the adoption of SAP policy prescriptions. Prior to the introduction of SAPs, ADMARC played a key role in the provision of extension services, which ensured proper handling of all pre- and post-harvest processes. These extension services helped to control the levels of contamination and facilitated meticulous grading of groundnuts. ADMARC could only buy groundnuts from smallholder farmers that were properly graded. ADMARC also had a facility at Liwonde to check for aflatoxin contamination levels and it only exported high quality groundnuts. The following sentiments of some of the key stakeholders are illustrative of the key role ADMARC played in the groundnut export trade:

Farmers have not been interested in grading their groundnuts as... [previously] ADMARC commanded almost singlehandedly the entire groundnut value chain. Vendors, as well as companies that farmers sell their groundnuts to, do not demand grading at all. They do the grading themselves, a practice that has spilled [over] to other crops such as tobacco, in which handling processes increase chances of groundnuts getting contaminated with aflatoxin. There is a lot of cheating, essentially, poor management of the value chain. (Interview with a Chief Executive Officer of a farmer organisation, 16 July 2020)

Grading of groundnuts and its proper handling was a must... farmers had to meticulously grade their groundnuts before taking it to the ADMARC market. Today, the groundnuts are carelessly handled, different grades [are] mixed, and farmers include rotten groundnuts 
to enhance volume, thereby increasing chances for contamination with aflatoxin. (Interview with a former official of NASFAM, 28 July 2020)

Liberalisation spoilt groundnut trade. The coming in of vendors and the rollback of ADMARC has destroyed groundnut farming. Vendors do not care about quality; they purchase whatever they get from farmers, yet previously ADMARC could only buy groundnuts from farmers that were properly graded. This practice has resulted in farmers selling groundnuts that are not properly processed and increases chances of contamination with aflatoxin. A question that I have is where do these vendors sell this poor quality groundnuts and what do the buyers do with it? (Interview with the President of the Farmers Union of Malawi [FUM], 24 July 2020)

According to Cook et al. (2014), aflatoxin levels rise due to poor drying practices, when water is used to soften shells, or when contaminated nuts are mixed with uncontaminated nuts. While aflatoxin contamination is an issue at both pre- and post-harvest stages in the value chain, NASFAM (2013) state that most of the post-harvest handling processes greatly enhance the chances of groundnuts becoming contaminated. Some of the constraints associated with poor postharvest handling processes include: the continued use of traditional methods of harvesting; limited knowledge in groundnut grading and value addition; shelling methods, such as the use of water during shelling, which render nuts susceptible to aflatoxin contamination; the use of unimproved storage facilities that increase the chances of post-harvest losses from pest and disease outbreaks; and limited knowledge of proper groundnut handling during drying and shelling.

Aflatoxin contamination still remains a huge barrier to Malawi's groundnut export recovery to levels that rival the peak in the 1970s and 1980s, despite concerted efforts to increase trade (Simtowe, Longwe-Ngwira and Siambi 2012). Both modern and traditional means have been deployed to limit aflatoxin contamination, but they have not yet yielded the desired results. The most credible means to detect and control aflatoxin levels is very expensive. This high liquid chromatography method costs around US\$230 per sample assessed, which is very expensive for the majority of farmers in Malawi. The alternative method, which is used in Malawi, is fairly affordable to farmers at about US\$1. However, this does not significantly promote the competitiveness of groundnut exports because it does not fully detect levels of aflatoxin contamination. This method is called the enzyme linked immunosorbent assay, which has been used by NASFAM and ICRISAT, but these organisations still send groundnut samples to accredited laboratories in South Africa to enhance the reliability of the decisions made. ICSRISAT established the Malawi Programme for Aflatoxin Control (MAPAC) in 2015 to ensure an integrated, nationwide approach to the problem (Dzanja, Kamkwamba and Matita 2017). With the scaled down involvement of ADMARC in the groundnut value chain, MAPAC has been the only nationwide initiative to control aflatoxin contamination in groundnuts. These efforts to develop the capacity to detect and control aflatoxin to acceptable levels continue with the aim to make Malawi's groundnut exports competitive. However, most of the interventions have either been project or programme oriented and, as such, they have failed to deliver the desired strategic impact.

The most notable traditional means to limit aflatoxin contamination thathas beendevelopedandencouraged among smallholder farmers is the Mandela Cock. The interviewees indicated that this method involves stacking groundnuts in a circle with pods pointing to the centre, while leaving a hole in the middle. This is mostly done in the field, where the groundnuts are left to dry slowly for 3-4 weeks. The Mandela Cock drying method for groundnuts reportedly gets rid of about 80 per cent of aflatoxin, especially since it allows for the nuts to dry slowly, which reduces their susceptibility to aflatoxin contamination. While this method is reasonably effective, 'it is, however, not widely used by farmers because most farmers who have used it have often experienced massive theft of their groundnuts... with rural livelihoods getting very tough petty theft is rapidly emerging as one of the most common survival strategies'.12

\subsubsection{Marketing challenges and constraints}

There are various forms of groundnut marketing outlets. These include, small aggregators, who buy from villages and sell to big vendors with warehouses; middlemen, who often operate at main market locations within trading centres or in a district's business area; big companies, which buy from middlemen; local cooperatives, which buy from members and non-members; and NGOs, which often buy from smallholder farmers that they have supported with seed (Itai 2020; Matita 2018). The major market for groundnuts produced by smallholder farmers is vendors. Scott and Chinsinga (2018) observe that

12 Interview with the Acting Chief Executive Officer of ADMARC, 21 July 2020 
smallholder farmers in Malawi lack access to lucrative, structured, and predictable markets, locally and internationally, following the collapse of ADMARC as the major marketing outlet for groundnuts. ADMARC was exporting groundnuts which it bought from the farmers. Depending on the nature of the export market, 'ADMARC was offering farmers bonuses for each $\mathrm{kg}$ of groundnuts sold to it that had been exported... this was called "champini" meaning "for the hoe handle" which could between MK1 and MK10'13 This motivated farmers to step up production because 'the bonus that we are talking about gave farmers an additional injection of cash that proved handy for them to procure inputs, especially fertiliser, for the next farming season'.14

While middlemen play a critical role in providing markets to desperate farmers, the market leaves a lot to be desired. As already observed, middlemen offer very low prices and often tamper with weighing scales. In the Malawi context, without middlemen, farmers would not be able to access cash, especially in the remotest areas, which is vital for them to meet some of their day-to-day needs. In addition, the middlemen create employment, especially among rural youth, who serve as their buying agents. These agents get a very low commission, but it helps them to survive. Middlemen continue to thrive because efforts to establish cooperatives in these remote areas, to facilitate bulk marketing and bargaining for better prices, have failed (Chimombo 2018). Middlemen need to be nurtured so that they can provide the missing market, but in a way that at least allows farmers to meet their production costs, as well as make a reasonable profit to sustain farming as their principal means of livelihood.

The disappearance of lucrative and predictable markets has greatly contributed to the apparent low productivity of groundnuts in the country. The dominant groundnut market offered by vendors is characterised by a great deal of price fluctuations, which affect farmers' decisions and marketing behaviour. There are two further challenges associated with this particular market. Vendors often offer very low prices, which are sometimes far below the minimum prices set by the government. They are also known for tampering with measuring scales to exploit farmers. In addition, vendors tend to start buying groundnuts too early in the season, often in April, which raises food safety issues related to aflatoxin levels in food consumption (Matita 2018; Mgalamadzi 2018).
Alternative markets provided by NGOs and cooperatives are not deemed profitable either. Itai (2020) indicated that some farmers are engaged in some form of contract farming with NGOs, where they are expected to sell their groundnuts only to the NGOs that provided them with seed. Farmers' complaint is that this arrangement limits their market value and opportunities. The main thrust of the farmers' sentiments, according to Itai (2020), is that, 'these NGOs bring seed to us when we have nothing to plant in our fields... and for us to... [receive the] same assistance the following farming season we are obliged to sell to them as per our agreement, although we do not benefit much'.

\subsubsection{Productivity constraints}

There are several factors that have combined to constrain the productivity of groundnuts in the country. Firstly, climate change poses challenges to the productivity of many crops including groundnuts. The productivity of groundnuts is negatively affected due to erratic rainfall and dry spells, especially during critical periods of growth and development (FARA, ZEF and AICC 2015; NASFAM 2013). The main challenge is that groundnuts are cultivated entirely as a rain-fed crop. There are some farmers that grow groundnuts in wetlands, especially in Mchinji, 'but they have not been encouraged and supported by extension efforts to popularise this as an alternative means of growing groundnuts'.15 While climate smart agriculture is widely practiced for other crops, especially maize, not many farmers do it for groundnuts. 'This is down to conflicting message[s] about climate smart agriculture, which makes it difficult for it to achieve the desired strategic impact'.16

Secondly, many farmers are reluctant to cultivate groundnuts on an extensive scale because it is a labour intensive crop. It competes for labour with other crops, especially tobacco and maize, hence, many farmers rarely cultivate more than 0.5 ha of groundnuts. Investment in groundnuts on a larger scale can only be promoted through mechanisation at different stages of the groundnut production cycle. Mechanisation in the harvesting and shelling of groundnuts can greatly help to boost investment in groundnuts. These two tasks are disliked by farmers and limit their investment in groundnut production because they are quite labour intensive. They require heavy labour commitments, 'which most farmers do not regard as [a] worthwhile

13 Interview with one of the big local traders, 12 August 2020

14 Ibid.

15 Interview with the President of FUM, 24 July 2020

16 Interview with the Chief Executive of a farmers' organisation, 19 July 2020 
opportunity cost... this is why ADMARC is considering investing in shelling technology so as to attract more farmers to engage in groundnut production.'17

Thirdly, there are limited credit facilities that support farmers to cultivate groundnuts, especially on a larger scale. Since the implementation of SAPs, the country has struggled to put in place viable credit facilities to support farmers in the agricultural sector. Access to improved seed and related inputs is very challenging, since ADMARC wound up the Smallholder Agriculture Credit Administration in 1994. The alternatives that have emerged are 'not farmer friendly because they levy very high interests that make farming less profitable and attractive as a principal means of livelihoods'. ${ }^{18}$ The underlying argument is that, 'without viable credit support facilities, people in rural areas cannot afford to invest in groundnuts on a larger scale because groundnut is a seed intensive crop, yet it is very expensive'. ${ }^{19}$

Although groundnuts are showing recovery signs in terms of productivity, production levels remain very low. The production of groundnuts has, thus, not kept up with the demands of both local and export markets in terms of volume (Matita 2018; Mgalamadzi 2018; NASFAM 2013). In summary, the low productivity of groundnuts is attributed to reliance on small-scale traditional groundnut farming husbandry practices; poor access to improved seed materials, resulting in recycling of planting materials; limited private sector involvement in improved groundnut seed multiplication; poor crop husbandry practices, resulting in declining soil fertility levels; erratic rainfall and dry spells during critical periods of plant development and growth; low adoption of improved technologies; and pest and diseases (FARA, ZEF and AICC 2015; NASFAM 2013).

17 Ibid.

18 Interview with an official of the Grain Traders Association of Malawi (GTAM), 22 August 2020

19 Interview with the Acting Chief Executive Officer of ADMARC, 21 July 2020 
Several factors have led to the re-emergence and recovery of the groundnut value chain. These factors either singularly, or in combination, have led to the recovery of groundnut production, especially since the turn of the 2000s. However, this recovery in production has not been matched with an equal recovery in exports (Mgalamadzi 2018; Simtowe, LongweNgwira and Siambi 2012). Formal exports remain very low. It is, in fact, estimated that only 1 per cent of groundnuts produced in Malawi are exported through formal structured markets namely: the Agricultural Commodity Exchange (ACE) and the Auction Holdings Limited Commodity Exchange (AHCX). Yet, it is reported that about 40 per cent of groundnuts produced in Malawi are exported within the region and even beyond. It is estimated that 60-90 per cent of groundnut exports from Malawi are through informal markets and largely through unchartered routes. One of the major concerns, however, is that there are some local processors, especially the manufacturers of therapeutic products, who are forced to source groundnuts from outside Malawi. This underscores the fact that high levels of aflatoxin contamination remain a huge barrier for Malawi's groundnuts to break into the orbits of lucrative local, regional, and global markets. Simtowe, Longwe-Ngwira and Siambi (2012) observe that substantial opportunities exist for export to the Common Market for Eastern and Southern Africa and the EU, as well as well as to South Africa, Tanzania, and Zimbabwe.

Factors that are driving the re-emergence and recovery of the groundnut value chain can be distinguished into three main categories. These are: 1) the progressive decline of tobacco as a major cash crop; 2) NGO and donor initiatives to revamp the groundnut sector; and 3) government policies that have either directly or indirectly promoted groundnut production.

\subsection{The decline of tobacco}

Tobacco is the major cash crop for Malawi. It accounts for about 63 per cent of total export earnings (FARA, ZEF and AICC 2015). This makes Malawi the most tobacco dependent country in the world. Smith (2018) illustrates the magnitude of Malawi's dependency on tobacco. She estimated that in 2015, tobacco comprised 30-40 per cent of total exports, making up 11 per cent of the country's GDP and 60 per cent of its export earnings. The paradox, however, is that while tobacco is clearly an important source of foreign exchange earnings at the national level, most tobacco farmers in Malawi live in poverty.

Part of the reason that most farmers do not benefit from tobacco farming is the progressive decline that the crop has experienced, especially since the turn of the 1990s. A combination of factors, such as the decline in tobacco quality, a decrease in yields, and increased transport, transaction, and marketing costs, have progressively decimated the benefits that accrue to farmers (Prowse and Grassin 2020). The genesis of this decline is attributed to the neoliberal policy reforms. Among other things, these reforms allowed smallholder farmers to participate in the cultivation of tobacco without adequate consideration of the institutional framework to prevent this shift from compromising the quality of the tobacco leaf offered on the market. These reforms were engineered by political elites, who did not have huge stakes in the industry, but saw these reforms as a means to get quick benefits for themselves. The reforms, for instance, allowed middlemen without any experience in handling tobacco to buy from farmers and sell the tobacco at the auction floors. The poor quality of the tobacco led to the progressive collapse of the tobacco industry. This has left the country with essentially no productive sector, especially since the rejection rates for tobacco leaf have soared to about 60 per cent in recent growing seasons. Moreover, since the 1990s, there have been accusations that prices at tobacco auction floors are fixed by companies acting like a cartel. A 2016 study is quite illustrative in this regard. Only 25 per cent of Malawian tobacco farmers were satisfied with the sales prices they received in 2014, and approximately 41 per cent had considered switching to alternative crops or livelihoods (Smith 2018).

The apparent decline of the tobacco industry has occurred despite the existence of a regulator, charged with the responsibility of overseeing standards in the sector. This task is performed by the Tobacco Control Commission (TCC). The work of the TCC was properly supported and facilitated during the one-party 
state regime, with the sole purpose of facilitating an institutional framework for successful production and extraction of rents. However, the situation changed quite substantially following the political transition in May 1994. The political elite that took power were not very interested in agriculture as a means of accumulating wealth, but rather commerce and industry (Chinsinga 2002). Their focus therefore shifted away from agriculture to commerce and industry, particularly through government procurement contracts. The TCC was equally captured by the new elite, who used it as a tool to neutralise the economic, political, and social power of the one-party elites. They did this by pushing for institutional reforms to the tobacco industry, which ended up compromising safeguards that promoted quality standards and professionalism. The institutional laxity that followed the capture of the TCC resulted in it losing its foothold of the industry and efforts to restore standards to the pre-transition period have effectively failed.

The decline of the tobacco industry is further attributed to the fierce anti-smoking lobby mounted within the context of the World Health Organization's Framework Convention on Tobacco Control (FARA, ZEF and AICC 2015). The anti-smoking lobby is driven by concerns about the health risks of smoking. The measures that are being promoted, such as raising cigarette taxes, bans on cigarette advertising, and the promotion of smoking restrictions, have greatly depressed global demand for tobacco (FAO). These measures, coupled with stringent demands for traceability, have forced Malawi to start looking for alternative crops to complement and, perhaps, replace tobacco as a major foreign exchange earner. It is against this background that groundnut production, previously dominated by women, is steadily emerging as a potential alternative crop. The sentiments of Malawi's former Minister of Finance, Dr Goodall Gondwe, are illustrative in this regard:

There is high demand for legumes on the world market and there is [a] stable market for it... tobacco has failed us, and legumes production is the way to go if we are to improve our socioeconomic standards as farmers and at the same time to improve our country's economy. (Mhango 2016)

The move towards legume farming is further bolstered by the decision by some tobacco firms to diversify their investment portfolio. According to some respondents to this study, companies like Limbe Leaf are diversifying into the production of legumes, especially groundnuts and soya beans, to cushion themselves from the unfavourable tobacco trade. 'This is creating fierce competition with smallholder farmers and, as such, there is need for the government to regulate their involvement in this sector'.20 There are also nontobacco companies that are moving into groundnut production on an extensive scale. Exageris is one such company, which is aiming to produce about 50,000t of groundnuts over the next 10 years, with a particular focus on the export market and value addition. This will be achieved through the company's own production on about 3,180ha and out-grower scheme arrangements with smallholder farmers. Exageris has already started production on its estate and is investing in research and development.

We are engaging in [a] variety trials in order to come up with groundnuts that will be productive in the hands of farmers, since most farmers do not realise potential maximum yields because they... use poor groundnut seed in the context of quite erratic climatic patterns. (Interview with the General Manager of Exageris, 30 August 2020)

\subsection{NGO and donor initiatives}

There are several NGOs and farmers' organisations that have played, and continue to play, a critical role in the re-emergence and recovery of the groundnut value chain. Notable farmers' organisations include NASFAM and FUM (Cook et al. 2014). These organisations, plus other NGOs, have been quite instrumental in mobilising farmers into clubs, associations, and cooperatives, which promote and market groundnuts, and hence contribute to the competitiveness of the crop (Simtowe, Longwe-Ngwira and Siambi 2012; Simtowe et al. 2009). Through concerted work on aflatoxin reduction measures with smallholder groundnut farmers, in partnership with a Fairtrade organisation, Twin Trading Ltd, NASFAM has resurrected the European export market. About 4,000 farmers, many of whom are women, have been able to better manage production and post-harvest handling to reduce aflatoxin to acceptable export levels. However, premiums are small and the farmers are somewhat discouraged by not seeing their income grow as expected (Cook et al. 2014).

Although NGOs' and farmer organisations' efforts to support the groundnut value chain have registered some success, there is still a very long way to go. According to Farm Radio International (2013), most small-scale farmers in Malawi are not organised, they produce and market their groundnuts individually. It is, in fact, estimated that out of the 100,000 groundnut 
farmers in the country, only 15,000 operate in clubs, associations, and cooperatives. This means that as high as 85 per cent of groundnut smallholder farmers remain unorganised. Unorganised farmers cannot fully and effectively participate in the groundnut value chain because they lack bargaining power to make their participation profitable. Some NGOs have contributed to reviving the groundnut value chain by making improved seed available to farmers through various schemes (Itai 2020). As stated already, the major complaint about these schemes is that farmers feel that they are sometimes exploited because they have to repay huge volumes of groundnuts and they are restricted to the markets offered by these NGOs, even when alternative lucrative markets exist.

Donors have been instrumental in reviving the groundnut value chain in various ways. As already indicated, USAID and Irish Aid have been critical to improving farmers' access to improved groundnut seed. These donors have invested massively in the development of the groundnut seed system in Malawi, which has essentially been neglected by the public sector (Simtowe, Longwe-Ngwira and Siambi 2012). To reiterate, the major drawback is that while these donors have spearheaded the development of a wide variety of groundnut seed through ICRISAT, many of these varieties are yet to be released for farmers to use due to financial constraints. Consequently, 'farmers still predominantly cultivate Chalimbana, which is out of favour in the export markets, and CG7, which is okay but highly susceptible to aflatoxin, making it difficult for it to fully break into export markets'. ${ }^{21}$

Recent USAID support has been channelled through a project called Feed the Future Malawi: Integrating Nutrition in Value Chains (FtF-INVC). This is an integral part of the US government's global initiative to sustainably reduce poverty and hunger. One of FtFINVC's initiatives aims to expand access to markets for smallholder farmers involved in growing soya beans and groundnuts, which are the two key value chain crops it is promoting. Since its launch, FtF-INVC has been organising buyers' tours, which have included Rab Processors, Estrell Trading Company, Exageris, ACE, and Sunseed Oil (Masangati 2016). The purpose of these tours is to help the private sector appreciate the quality of crop available, while ensuring that farmers have the opportunity to negotiate better prices for their products. In addition, FtF-INVC promotes, supports, and facilitates gender equitable, market driven, agriculture led, and integrated economic growth.

The Development Fund of Norway supports the Legume Development Trust, which was initially established in 2008 by Malawi's Research Into Use organisation. Known as the Legumes Platform in 2008, its main goal was to contribute to overall food and nutrition security and income generation in Malawi. The Legumes Platform intended to achieve this goal through resilient and sustainable seed systems, which would spur increased legume productivity at farm level, resulting in increased legume use at household and industrial levels (UNIDO 2012). The coordination of the Legume Development Trust is now handled by the African Institute for Corporate Citizenship, which has revived it to promote the productivity of legumes with a particular focus on groundnuts. The other legumes include soya beans and pigeon peas. In its reconstituted form, the Trust comprises of consumers, policymakers, traders, and financial institutions. It has been reorganised into four technical working groups, namely: production, marketing, processing and value addition, and policy. The main tasks of the Trust include the following: promoting an effective legume seed supply system; farmers' empowerment and organisational development; promoting technology transfer; linking legume farmers to high value markets; enhancing farmer productivity; and introducing higher valued added activities within the value chain.

\subsection{Government policies and programmes}

The government has implemented several policies and programmes that have, in different ways, contributed to the revival of the groundnut value chain in the country (UNCTAD 2019; UNIDO 2012). These policies and programmes are essentially designed to support the production of high quality groundnuts with lower aflatoxin levels. Achieving acceptable aflatoxin levels to trade in global markets would enable groundnut farmers to enjoy the benefits of high global prices, which increased at an average growth rate of 7.2 per cent during the period 1991-2006. Most of the policies and programmes have been inspired by the Malawi Growth and Development Strategies (MGDS I, II, and III), the country's five-year mid-term rolling planning framework. The agricultural component of the MGDS is influenced by and responds to the Comprehensive Africa Agriculture Development Programme (CAADP). The CAADP requires signatory countries to invest at least 10 per cent of their national budget in agriculture, which leads to an estimated 6 per cent annual growth in GDP and improves rural livelihoods.

It is against this backdrop that MGDS I to III have consistently promoted the diversification of agricultural production to include high value commodities for export, with the aim to promote food security,

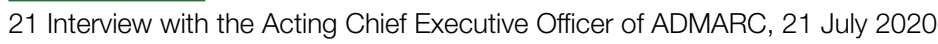


economic growth, and wealth creation. The Agriculture Sector Wide Approach (ASWAp) (2008) was developed to achieve these goals. The ASWAp has since evolved into the National Agricultural Investment Plan (NAIP), which is a medium term investment framework for the agricultural sector, covering the period between 2018 and 2023. Both ASWAp and NAIP recognise commercial agriculture, agro-processing, and market development as key priority areas that must be supported in order to boost the country's economy and increase general levels of prosperity. The NAIP continues with the ASWAp's goal of seeking to increase economic returns to smallholder farmers by enabling the production of aflatoxin-free groundnuts, which could be exported into more lucrative international markets (UNCTAD 2019; UNIDO 2012).

Through FISP, the government was able to provide beneficiary farmers with improved groundnut seed, which progressively improved the productivity of groundnuts (NASFAM 2013; UNIDO 2012). Implemented initially as an integral part of ASWAp, and later NAIP, the decision to include legume seed in the FISP package was meant to encourage crop diversification to promote better nutrition for farmers, improve their soil fertility, and enhance their incomes through domestic and export sales. Although farmers' access to improved groundnut seed through FISP was somewhat erratic, due to the scarcity of improved seed, some farmers received improved seed, who would previously have been unable to access it. This greatly contributed to the increased groundnut productivity that has been observed, especially since 2008 .

The implementation of the National Multi-Sector Nutrition Policy has further contributed to the recovery in groundnut productivity in Malawi. This policy, first developed in 2007, aims to improve the nutrition status of all Malawians, with an emphasis on children under five-years-old, pregnant and lactating women, school aged children, and other vulnerable groups, such as people living with HIV and people affected by emergencies (GoM 2018). As part of the policy's implementation, the government runs a therapeutic programme in all government and mission hospitals, which involves the provision of groundnut paste, locally known as 'chiponde', to malnourished children and HIV/AIDS infected patients. This groundnut paste is mostly sourced from locally owned companies. The programme has greatly contributed to the improvement in groundnut productivity because it is aligned to the government's goal to transform the groundnut subsector from a subsistence oriented sector to a more commercially oriented sector. Several organisations are therefore implementing innovative arrangements to link farmers to markets and to reduce transaction costs associated with activities along the supply chain, for example, storage, product control, standardisation etc. (UNIDO 2012).

Simtowe et al. (2009) highlighted the weather indexbased groundnut insurance scheme as one of the most progressive institutional innovations towards the promotion of groundnut production in Malawi. This was prompted by the worsening climatic conditions, which makes farming, especially groundnut farming, an extremely risky venture. With technical and financial support from the World Bank and Opportunity International, in partnership with NASFAM and Insurance Association of Malawi, the groundnut insurance scheme was initially launched in the districts of Kasungu, Lilongwe and Nkhotakota. The insurance scheme involves an index-based weather insurance contract, which pays out if the rainfall in a season is insufficient to support groundnut production. The insured crop can then be used by farmers as collateral for accessing credit from financial institutions. This enables groundnut farmers to purchase and plant certified groundnut seed. Using certified seed not only increases the farmers' productivity, but also their ability to control aflatoxin contamination in their groundnuts, thereby enhancing profits (UNCTAD 2019; UNIDO 2012).

Last, but not least, the National Export Strategy (NES) developed in 2012 has also contributed to the increased groundnut productivity. The NES is billed as the first coherent and integrated policy framework for the export sector. It provides a prioritised roadmap for developing the productive base of the economy to enable both export competitiveness and the economic empowerment of youth, women, smallholder farmers, job seekers, and the poor. The NES prioritises legumes, such as groundnuts and soya beans, for value addition and exports, especially in view of the world's campaign against tobacco production and utilisation (FARA, ZEF and AICC 2015; NASFAM 2013). The NES has been developed on the premise that groundnut and soya bean products are among the products with the highest potential for collaboration among stakeholders.

Notwithstanding these initiatives, there are several factors elaborated in this paper that constrain groundnut production. All these constraints point to the fact that some major structural transformations are needed to ensure substantial improvements in the productivity of Malawi's agricultural sector. In addition, the sector must increase its resilience to climate change to boost agricultural economic vitality, with a view to fully exploiting both domestic and export markets (Simtowe, Longwe-Ngwira and Siambi 2012). While formal groundnut exports are still constrained 
by aflatoxin contamination, the informal export trade, explored in detail in the next section, continues to flourish. There is a need to explore how high quality groundnut production can be promoted, while ensuring farmers' access to lucrative markets both domestically and externally. As hinted in the NES, the legume sector has the potential to promote sustainable, inclusive development in rural Malawi, creating a foundation for long-term resilient growth. 


\section{THE STRATEGIC NEGLECT AND CAPTURE OF THE GROUNDNUT VALUE CHATN}

There are two major stories that demonstrate the apparent strategic neglect and capture of the groundnut value chain. These stories are about the enduring contestations to establish export mandates for agricultural produce in the country and the emergence and entrenchment of the Mgona informal groundnut export market right in the heart of the capital city, Lilongwe. Mgona is one of the informal settlements in the capital city, within a $20 \mathrm{~km}$ radius from the seat of government, Capital Hill. These two stories are a great cause for concern because they constitute a paradox for Malawi, which is a predominantly agrarian economy, yet gets very little taxation proceeds from the agricultural sector. An official from one of the leading farmers' organisations observed that, 'the country is losing a lot of money from the agricultural sector; tax contribution from the agricultural sector is estimated at only 10 per cent, yet this is an agrarian economy... this is not surprising because most of the transactions are done informally'. ${ }^{22}$ While the agriculture sector contributes about 30 per cent to the country's GDP, employs about 85 per cent of the population, and generates about 60 per cent of rural income, it rakes in only 10 per cent of the total tax revenue. This is predominantly the case because of the salience of informal cross border trade (UNCTAD 2019; Gondwe and Baulch 2017). Ministry of Trade officials estimate that the illicit export of commodities such as groundnuts and soya beans, amount to about MK30 billion annually (The Nation 2020).

There is huge potential for Malawi's agriculture sector to raise substantial additional revenue to government coffers through formalised export trade. For example, with reference to the groundnut value chain, the potential export trade is estimated at US\$48.4 million, of which 52 per cent or US\$25.2 million remains unrealised (International Trade Centre 2018). There is great potential within the Southern Africa Development Community (SADC) region and even beyond, subject to the value chain's ability to decisively deal with aflatoxin challenges. Unrealised potential exists in traditional SADC markets (South Africa, Zimbabwe, and Zambia), as well as in Mozambique, where Malawi currently accounts for less than 4 per cent of all groundnut imports. It is estimated that Mozambique has an untapped groundnut export market to the tune of US\$2.2 million. Malawi's potential to exploit this market is hugely dependent on its ability to intensify its capacity to effectively compete with South Africa, which is currently Mozambique's biggest supplier (International Trade Centre 2018).

The stories about the contestations regarding the establishment of export mandates and the thriving Mgona informal groundnut export market, illustrate Malawi's failure to take steps that would enable it to enormously benefit from a formalised export trade in agricultural commodities. Since the 1960s, the Control Goods Act (CGA), which was revised in 2017, has regulated the importation and exportation of goods by restricting, banning, or allowing exports and imports under license. For agriculture based commodities, a trader is required to obtain an authorisation letter from the Ministry of Agriculture before applying for a license from the Ministry of Trade. This means that any trader who imports or exports licensable goods without a requisite license commits an offence punishable by law. Export mandates cannot be implemented due to fierce resistance from traders and limited commitment from political and bureaucratic elites, despite protracted efforts to do so, and the Mgona informal groundnut export market continues to thrive without any effort to regulate its obvious illegality.

The Mgona export market is described as informal even though there is some semblance of formal organisation on the basis of its overall operative dynamics, which seek to circumvent established government laws governing export trade in Malawi. This characterisation draws from the notion of informality propagated by Helmke and Levitisky (2004). Informality underlies socially shared rules, usually unwritten, which are created, communicated, and enforced outside of officially sanctioned channels. Both the export mandate and Mgona export market demonstrate the apparent strategic neglect and capture of the groundnut value chain by a small group of very well-connected business (local and foreign), bureaucratic, and political elites. These elites benefit from various streams of rent 
from the reigning chaos and disorder in the groundnut value chain. They are therefore resisting efforts to alter the institutional framework for groundnut export trade, which would change the distribution of rents currently obtained from it. This aligns with Khan's (2017) argument that stakeholders in a sector or otherwise can be expected to support, resist, or distort particular institutions or policies depending on their interests and capabilities.

\subsection{The establishment of export mandates}

\subsubsection{The origins of export mandates}

The efforts to establish export mandates build on the government's goal to establish structured markets as a solution to inefficiencies in the crop export market. According to Gondwe and Baulch (2017), a structured market is an organised and formal place where farmers, traders, processers, millers, banks, and other stakeholders enter organised and regulated trading and financial arrangements. While the Reserve Bank of Malawi Exchange Control Act of 2005 requires exporters to declare and remit export proceeds, some exporters either do not remit or under declare their export proceeds. Export mandates are therefore designed to curb the proliferation of informal cross border trade and expand formal export earnings by dictating that a commodity can only be exported through a structured market. Export mandates are becoming an imperative for Malawi due to declining export proceeds from tobacco, as a result of the anti-tobacco smoking campaign and volatile prices. Expanding export mandates beyond tobacco and tea - Malawi's major exports - to cover other commodities, such as soya beans, pigeon peas, sunflowers, and groundnuts, could help Malawi to diversify its export earnings in the face of declining demand for tobacco (Gondwe and Baulch 2017).

The emergence of structured markets for crops other than tobacco and tea can be traced back to 2006 when the ACE was established. This was followed by the establishment of the AHCX in 2013 (Nyondo, Nankhuni and Me-ksope 2018). The benefits of commodity exchanges as structured markets include enabling farmers to access collateral finance through warehouse receipt systems; providing better price premiums through aggregation and the enhancement of commodity quality; the reduction of post-harvest losses; the availability of up-to-date information on prices and trading processes; and smoothing surpluses that occur during harvest (Gondwe and Baulch 2017). Furthermore, commodity exchanges perform many vital functions, such as facilitating price discovery, promoting standardised contracts and grading systems, and enforcing contracts.

While export mandates have some advantages, they are not without any setbacks. The advantages of export mandates include increased volumes of formal trade; increased tax revenues through formal trade; improvements in the prices and revenues farmers receive; and the reduction of informal trade. On the other hand, the setbacks include the increased likelihood of creating a monopsony in crop export; heavy transport costs on the part of exporters; and the potential to cause informal market growth by encouraging more actors to circumvent exchange fees (Nyondo, Nankhuni and Me-ksope 2018; Gondwe and Baulch 2017).

The key players in the efforts to establish export mandates include government (Ministry of Agriculture and Ministry of Trade), commodity exchanges (ACE and AHCX), Malawian traders of Asian origin (Rab Processors, ETG, Farmers World, Agora, Transglobe, etc.), Malawian traders with political connections (Mulli Brothers and Simama General Dealers) and emerging Malawian traders (Ntalimanja Holdings, Takondwa Commodities, Dalitso General Dealers etc.), and development partners (FCDO, EU, and the World Food Programme [WFP]). All formal traders belong to the Grain Traders Association of Malawi (GTAM).

\subsubsection{The organisation of export mandates}

The Malawian government has designated ACE and AHCX as platforms for institutionalising export mandates in the country. These commodity exchanges will serve as organised structured markets for agricultural produce in the country. This means that, once effective, no agricultural produce will be exported without passing through either ACE or AHCX. This is going to improve the welfare of farmers because 'commodity exchanges offer competitive and transparent marketing of agricultural commodities'. ${ }^{23}$ Through commodity exchanges, suppliers links to buyers are guided entirely by quality and quantity considerations, which ensures farmers often receive decent returns. Potential buyers deposit money into the commodity exchange, which locks up business with suppliers 'once the suppliers agree with the price the buyer is looking for'. ${ }^{24}$ The major benefit for the commodity exchanges is the fees that are levied to

23 Interview with the Coordinator of one of the government's supported agricultural projects, 19 July 2020 24 Ibid. 
both suppliers and buyers. The proposal is that both the suppliers and the off-takers will be charged 2 per cent for transactions.

In the absence of export mandates, the government uses export bans to regulate exports. The commodities that are subjected to export bans include maize and legumes, in particular, soya beans and groundnuts (Scott and Chinsinga 2018). The introduction of export mandates will render the ad hoc export bans unnecessary, which, in turn, should increase the volumes of produce traded via structured markets. This would further allow a more stable and transparent policy environment that would permit private sector traders and commercial farmers to develop without fear of well-intentioned, but disruptive government interventions. The effectiveness of export restrictions, whether in the form of export taxes or quantitative limitations, can be further undermined by unregulated activities, which are not visible to authorities (Gondwe and Baulch 2017). The expectation is that once the export mandates become functional the country would start benefiting from the agricultural export trade. One of the interviewees for this study argued that, 'Malawi is like an open, [an] unfenced garden where monkeys are feasting on the green maize cobs without being chased or disciplined... these monkeys are both local and foreign exporters of agricultural produce from the country'. ${ }^{25}$

\subsubsection{Contestations about export mandates}

There is generally support for the introduction of export mandates, but there are disagreements about how they should be operationalised. These contestations, however, mask the deeper underlying incentives and interests that are behind the positions taken by the major protagonists in this process. Both commodity exchanges are considered too weak to direct their expected functions independently. This is attributed to the fact that the volume of trade taking place in these exchanges is too low for them to be effective. The proposal is that these two exchanges should be merged, 'but the practical modalities of doing so cannot be easily churned out and agreed upon'.26 The suggestion to merge ACE and AHCX is echoed by Gondwe and Baulch (2017). They argue that the volumes traded by both ACE and AHCX are rather low, casting doubt on the financial sustainability of each commodity exchange's operations. A merger would likely reduce operating costs through economies of scale and commissions, thereby enhancing the volumes traded and revenue in the long-term.

Stakeholders hold several reservations about both commodity exchanges. Most traders argue that ACE is not well suited to execute the export mandates because it is not well constituted as an impartial arbiter. They argue that ACE is both a trust and a commercial entity, which would compromise its dealings as a platform for commodity export transactions. The main challenge is that the 'ACE Board of Directors are also big commodity traders, which would invariably engender conflict[s] of interest'. ${ }^{27}$ Moreover, 'while we agree with the export mandate, we do not think ACE is the right institution because they have been unable to find viable export markets for their currently low levels of trade... we do not think they can find viable and lucrative markets when they get the authority to execute the export mandates'. ${ }^{28}$ While the export mandate regulations posit that big traders should not buy directly from farmers, ACE works directly with farmers. They give farmers $30 \mathrm{~kg}$ of groundnut seed and farmers pay back $150 \mathrm{~kg}$, leaving farmers with excess production to find markets on their own. The concern is that while ACE has a commodity trading license, they engage in barter trading (the exchange of groundnuts with groundnuts instead of using money as a medium of exchange), which is not creating a market for farmers.

Many stakeholders feel strongly that ACE survives because of its strong reliance on donor support in its guise as a trust. In particular, as a trust ACE is able 'to capture donor money through lucrative contracts... ACE has been procuring maize for WFP, which it uses to support school feeding programmes... ACE also gets contracts to supply donors' maize for humanitarian causes'. ${ }^{29}$ Had it not been for these contracts, the argument is that ACE would have folded because 'it would not be able to pay salaries for its employees as it does not make enough money on the platform' ${ }^{30} \mathrm{AHCX}$ is equally unsustainable as it is hugely dependent on government business. A member of GTAM concluded that 'both $\mathrm{ACE}$ and $\mathrm{AHCX}$ are dead institutions: ACE cannot survive without donors and AHCX without government preferential support'. ${ }^{31}$ In their current state, stakeholders argue that both ACE and AHCX are not ready to implement the export mandates. They both lack the requisite infrastructure, such as warehouses and quality assurance facilities, to mediate

25 Interview with one of the emerging local commodity traders, 10 August 2020

26 Ibid.

27 Interview with a member of GTAM, 15 August 2020

$28 \mathrm{Ibid}$.

29 Interview with one of the leading Agricultural Economists in Malawi, 24 August 2020

30 Ibid.

31 Interview with a member of GTAM, 28 July 2020 
the execution of export mandates. Moreover, both have dismal track records in identifying lucrative export markets for agricultural produce. An International Food Policy Research Institute (IFPRI) study has, in fact, concluded that commodity exchange platforms in Malawi have not benefited farmers (Nyondo, Nankhuni and Me-ksope 2018).

Most stakeholders are concerned that while the government is aware of these limitations, it is still keen to designate export mandates as an exclusive domain for ACE and AHCX. This is raising a great deal of suspicion among stakeholders about collusion between government officials and the owners of the commodity exchange platforms. Many fear that those colluding want to exploit the fees that suppliers and buyers will be paying to promote selfish interests. Given the hybrid nature of ACE, some stakeholders felt the operational fees could be exploited to finance its commercial component, systematically frustrating or undercutting the emerging local traders. Moreover, there is a strong feeling that export mandates risk undermining contract farming due to the lack of flexibility in the trading arrangements. Some of the local traders felt that:

The imposition and enforcement of export mandates will be a huge deterrent to commercial farmers because they will be forced to sell through either ACE or AHCX, which, through the exorbitant fees, will be reaping where they did not sow and using the same proceeds to undercut us. (Interview with a member of GTAM, 28 July 2020)

However, some of these traders have strong links to the thriving Mgona informal groundnut export market, which is fully explored in the next section. These traders are therefore very unlikely to patronise ACE/ AHCX platforms unless they are forced. As such, they will resist the formal implementation and enforcement of the export mandates to continue benefiting from the streams of rents proffered by the Mgona informal groundnut export market.

The export mandates cannot be effectively implemented, let alone enforced, due to the fierce resistance of a very well-organised cartel of traders, which have some strong political connections. Some of these companies are entirely Malawian companies, while others are owned by Malawians of Asian origin, which have sister companies either in the Middle East or Asia. While the Malawian companies exploit their political connections to delay the implementation of export mandates, the companies owned by Malawians of Asian origin exploit transfer pricing through their sister companies elsewhere. These companies buy from farmers cheaply and export to their sister companies by under declaring the volumes exported, as well as the price at which these commodities were actually procured. They resist the introduction of export mandates because once they come into effect, they will not be able to directly buy from farmers and they will not have the liberty to under declare the volumes of their exports. This cartel has captured both politicians and technocrats:

The members [of this cartel] bankroll the politicians or give them a slot to export their share... so too technocrats, who, in turn, are not able to enforce basic policy guidelines regarding commodity export, which are clearly provided for in the CGA, 2017. (Interview with one of the emerging local commodity traders, 29 July 2020)

All this happens behind the scenes, but it explains the protracted delays or lack of progress in the promulgation let alone enforcement of export mandates.

The alternative proposal by most stakeholders, especially emerging local commodity traders, is that ADMARC should be vested with the authority to execute the export mandates on an interim basis for at least two years, while the government works on a permanent framework. Given the inherent challenges of ACE and AHCX, 'ADMARC is better suited for this role because it would serve as a genuine impartial arbiter' ${ }^{32}$ In addition, ADMARC has a previous credible track record serving in a similar role and, 'it would be a way of guaranteeing that proceeds from commodity export trade are being ploughed back into the economy for the benefit of Malawians'. ${ }^{33}$ Unlike both ACE and AHCX, ADMARC has an extensive infrastructure network, which it can effectively utilise for this purpose. The paradox, however, is that government is still determined to vest authority for export mandates in ACE and AHCX. This 'raises suspicion of organised rent extraction, when these two platforms do not clearly have the requisite capacity'. ${ }^{34}$

The advice to government by most of the technocrats and traders was that it should learn from the successes of Ethiopia and Rwanda. These two countries have

32 Interview with a member of GTAM, 10 August 2020

33 lbid.

34 Interview with an official from the Ministry of Agriculture, 24 July 2020 
managed to establish robust commodity exchange platforms, which are effectively executing export mandates. In both cases, they indicated that the government played a critical role. The commodity exchange platforms started off as fully government owned until all the relevant systems were developed and fully functional. It was only after they became fully functional that the government began to progressively divest ownership to the private sector. The underlying argument is that 'viable commodity exchange platforms executing export mandates cannot be effectively established unless government takes bold steps to fight deeply entrenched donor and business interests'. ${ }^{35}$ This is imperative, especially now that 'the country is financially bleeding: tobacco is not doing well; it is not bringing in enough money to effectively power the country's economy'. ${ }^{36}$ Thus, without organised markets, the country is losing a lot of export revenue that would otherwise help to power the development of Malawi.

\subsection{The Mgona informal groundnut export market}

\subsubsection{The origins of the market}

The Mgona informal groundnut export market is dominated by East African citizens, especially Burundians, most of whom initially came to Malawi as refugees. They have established a reputation for themselves as versatile entrepreneurs in various sectors. As such, they are generally treated with envy by local Malawians. They often prosper within very short periods of time when they venture into any economic endeavour. The market runs essentially from March to December every year, although practically speaking, it is an all year round affair.

The market is supplied in several different ways. Farmers from groundnut growing districts, especially Kasungu, Mchinji, and Ntchisi, bring their groundnuts to Mgona for sale. Alternatively, vendors go out to buy groundnuts from farmers in the groundnut producing areas, which they, in turn, sell to the Mgona market. Interviewees for this study indicated that they started off the 2019/20 season buying groundnuts at MK3,500 per 201 pail. At the time of the fieldwork for this study, the price had peaked to MK4,000 per 20l pail. Some of the Burundian traders commission vendors to buy groundnuts on their behalf from farmers. These vendors are either commissioned from Lilongwe or contracted in their respective villages as groundnut buying agents. They get commission depending on the volume of groundnuts bought. For some of the buying agents, especially those contracted from their respective villages, engagement in this value chain has been a life changing experience, as reported in several life histories (Chinsinga et al. 2020). Furthermore, Burundian traders loan money to farmers to grow groundnuts on the understanding that the groundnuts will be sold to them. The money is meant to help farmers buy inputs and take care of the groundnut fields to guarantee high productivity. A small number of Burundians lease land to cultivate groundnuts themselves, which they process for sale through the Mgona informal groundnut export market.

\subsubsection{The market processes}

Groundnuts are brought to the Mgona market unshelled. So, the first task for the farmers or the vendors is to get their groundnuts shelled. The development of this market has prompted some innovation in groundnut shelling technology, which includes both manual and electronic groundnut shellers. Strikingly, all electric groundnut shelling machines are owned by Burundians, while nearly all manual ones are owned by locals, who have innovated their modelling based on the electronic groundnut shelling machines. These machines have played a key role 'in facilitating the growth and development of [Mgona] groundnut market, since hand shelling is a labour intensive exercise or undertaking', ${ }^{37}$ The charge for the manual shellers is MK700 per $90 \mathrm{~kg}$ of groundnuts, while the charge for electric shellers is MK700 per $50 \mathrm{~kg}$ of groundnuts.

The next stage is to get the groundnuts sieved and graded so that they are ready for sale to Burundian buyers. These two stages are exclusively women's domain. The women charge MK600 per $50 \mathrm{~kg}$ bag to sieve groundnuts, while grading costs MK400 per $50 \mathrm{~kg}$.

The market for groundnuts is quite dynamic. The prices are responsive to the forces of demand and supply: '[prices] even vary within a day three or four times, so one has to be on the look out to make sure you get the highest price for the day'. ${ }^{88}$ While all the groundnuts are bought by Burundians, there is some differentiation among the buyers. The initial buyers of groundnuts are mostly agents for other richer Burundians, who give them money to buy groundnuts. They, in turn, get a MK10/kg commission for the total volume of groundnuts purchased. The Mgona market is attractive to farmers from groundnut growing districts because the prices at which the Burundians buy groundnuts are often about twice the minimum prices set by government. For the 2019/20 market season, for example, the price

35 Ibid.

36 Interview with the Manager of an agricultural commercialisation project supported by the World Bank, 31 August 2020

37 Interview with a vendor at the Mgona informal groundnut export market, 10 September 2020

38 Interview with a vendor at the Mgona informal groundnut export market, 10 September 2020 
of groundnuts at Mgona market peaked at MK870/kg compared to MK400/kg set by the government. Some of the Burundian merchants revealed that some of the groundnuts are sold locally to companies engaged in the production of government paste and peanut butter.

\subsubsection{The export market}

The main export destinations for groundnuts from Mgona, Lilongwe, are Dar es Salaam and Nairobi, 'but the groundnuts do get as far as Kampala, Kigali, Bujumbura, and even Kinshasa'. ${ }^{39}$ The widespread perception is that Mgona groundnut exports target low end markets, which are not bothered about aflatoxin levels. Malawi's groundnuts end up on the streets of most capitals in East Africa.

One of the respondents interviewed for this study indicated that he tried to participate in Mgona export market, but could not get tangible information about it. He concluded that, 'this is a different type of market that [re]lies on social networks and social capital throughout the value chain'. ${ }^{40}$ This means that to participate in this market, one must know people every step of the chain, including at the other side of the market. He emphasised that, 'the actors in this market are able to speak the same language: Malawians do not have the language to participate directly in this export market chain', ${ }^{41}$ An official from one of the farmer organisations drew parallels to the cassava market in Lilongwe. He observed that the cassava market at the Lilongwe Central Market is highly protected to the extent that, 'even when there is no cassava in town, no supplier outside the allowable circuit can sell cassava... if they do, the consequences are dire'. ${ }^{42}$

The main concern for most stakeholders is that this export market is creating a parallel foreign exchange system. On their way back, the trucks that transport the groundnuts to export markets are loaded with assorted merchandise for sale in Malawi. A disproportionate share of the merchandise constitutes Unilever products, which are sold to wholesalers to make supernormal profits. All this trade is reportedly circumventing the formal trade protocols and controls. While GTAM members regard this market as unimportant, describing it as the export of groundnut husks, interviews with the traders and exporters revealed that some of the leading groundnut processors purchase their groundnuts from the Mgona market. The following sentiments capture the underlying dynamics of this export trade:
We have seen rampant informal export trade of local products, largely by foreign traders, to our disadvantage because we follow formal procedures and channels: they create unfair competition, they bring in dollars and change [their money] at the black market with higher margins, then [they] buy and export informally at higher profits, which give them an upper hand (Chilundu 2020).

Most GTAM members described the Mgona informal groundnut export market as not something to worry about as, 'it is simply a vendor market; the quality of groundnuts traded there is very poor... it is a market that deals with groundnut rejects'. ${ }^{43}$ Some other respondents interviewed for this study argued that, 'GTAM members described what is exported as merely husks, and not necessarily groundnuts, yet they deliberately mix the groundnuts with husks as a strategic ploy to evade custom requirements'. ${ }^{44}$ GTAM members described the thriving Mgona informal groundnut export market as a sign of the failure of structured markets in Malawi. The underlying argument is that the market failures, manifested in the thriving informal groundnut export market, underpin the failure of the government to take responsibility.

\subsection{IImplications for the groundnut value chain}

GTAM's trivialisation of the Mgona informal groundnut export market and the government's inaction, which allows the market to thrive, despite the Control Goods Act (CGA) requiring every export trader to be licensed, raises several questions. The trading is done openly and the trucks transporting groundnuts pass through the borders with groundnuts on the way out and assorted merchandise on their way back. These trucks are not apprehended at all. The issue has reportedly been discussed in several meetings involving government officials, traders, CSOs, and development partners, but no concrete action has ever been taken. The conclusion is that the system is captured. It appears that some GTAM members, politicians, technocrats, and independent Malawian traders are benefiting from this market. They are supplying this market through their Burundian surrogates. This seems a plausible explanation because of the blatant illegality of this market, which would otherwise have faced efforts to thwart it altogether or, at least, to formalise it, given that it has been a subject of intense discussion in several

39 Interview with a Burundian trader at Mgona informal groundnut export market, 10 September 2020

40 Interview with an emerging local trader, 16 August 2020

$41 \mathrm{lbid}$.

42 Interview with an official of one of the farmers' organisations, 28 August 2020

43 Interview a member of GTAM, 6 August 2020

44 Interview with an official of one of the farmers' organisation, 8 August 2020 
policy forums. The government is losing considerable revenue due to voluminous informal groundnut exports. Both the failure to implement export mandates and inaction to curtail the Mgona informal groundnut export market demonstrate, inter alia, that policy processes are often deeply imbued with the clash of competing interests and viewpoints (Chinsinga 2018; Araujo, Acosta and Saiegh 2004). In fact, politics plays a crucial role in shaping development outcomes, when construed as contestation and bargaining between interest groups with competing claims over rights and resources.

The political interests that prevent the implementation of impartial and objective policy solutions mean that the apparent recovery in the productivity levels of groundnuts - due to the decline of tobacco, support from donors/NGOs, and government policies and programmes - will not benefit the country's quest for increased income from the agricultural sector. The net benefit from the productivity recovery of the groundnut value chain is likely to remain limited, especially to the government. The country is producing groundnuts that cannot be competitive in the formal markets. Even when opportunities exist to improve the quality of groundnut production, farmers are reluctant to take these up because they are still able to benefit immensely from their low quality groundnuts through the vibrant Mgona informal groundnut export market. To reiterate, the buyers in this market are not concerned about the quality of groundnuts they get from farmers. Politicians and technocrats benefit from the current state of affairs, which has resulted in them dragging their feet in implementing export mandates that would formalise the trading of all major crops in the country, including groundnuts. 


\section{SOCIAL DIFFERENTIATION IN THE GROUNDNUT VALUE CHAIN}

The following examination of social differentiation in the groundnut value chain principally focuses on three areas: 1) barriers to entry and/or requirements for participation in the value chain; 2) the ability of participants to improve their performance; and 3) the differences between and among participants' access to and control over the benefits from the value chain. An additional fourth area of focus relates to the underlying dynamics of the Mgona informal groundnut export market, which further magnify the social differentiation processes and their implications for the different participants in the market. The discussion on the first three elements of social differentiation in the groundnut value chain draws heavily from the work of Cook et al. (2014), which has been amplified by insights from stakeholder interviews conducted for this study. Cook et al. (2014) explore social dynamics in three different value chains, namely: groundnuts, soya beans, and dairy. The processes of social differentiation in the groundnut value chain can be fully understood when placed in the broader context of social differentiation in rural Malawi. The processes are partly underpinned by the liberalisation of burley tobacco cultivation and the emergence of medium-scale farmers, especially since the turn of the new millennium. The processes of social differentiation are exacerbated and magnified, in some instances, by the underlying dynamics of intersectionality, whereby different markers of either advantage or disadvantage coincide to promote positive benefits or deepen social disadvantages, respectively.

\subsection{Social differentiation in rural Malawi}

\subsubsection{The liberalisation of burley tobacco cultivation}

The cultivation of burley tobacco was liberalized in the early 1990s. Until the liberalisation, the cultivation of burley tobacco was the preserve of the estate subsector (Chinsinga 2018; Masanjala 2006). As part of the SAPs, the cultivation of burley tobacco was opened to smallholder farmers as a potential solution to Malawi's development impasse. According to Prowse and Grassin (2020), tobacco production would kick-start productivity increases in the smallholder sub-sector for both food and export crops, as well as stimulating demand for goods and services in the non-farm rural economy. Through burley cultivation, Malawi would make significant strides in the fight against poverty and food insecurity. The cultivation of burley tobacco would enable smallholder farmers to access decent cash incomes to allow them to buy food from the market or buy productivity enhancing inputs that would facilitate the production of both cash and food crops on an extensive scale.

This historic change in Malawi's agrarian set-up triggered massive social differentiation on two fronts. The cultivation of burley tobacco was dominated and monopolised by men. Not all men, however, dominated the cultivation of tobacco. It was mainly those from better off families (those owning generally no less than 5ha of land) to allow for the cultivation of burley tobacco and other crops. Most of these men were connected to families that are influential in the village setting (traditional leaders; established businesses; senior retired public service employees; local political leaders, especially those connected with the political party in power; and government frontline workers, such as extension workers, community development assistants, health surveillance assistants, and even primary school teachers). Most of these categories of men are able to raise capital to invest in the cultivation of burley tobacco through their social networks, including through opportunities offered by external agents such as cooperatives, NGOs, and even tobacco companies. Some poorer men, and the majority of male youth, have been working as casual labourers in the tobacco gardens of the better off farmers. Most of the poorer men do not have adequate land, they usually farm on less than 1ha and struggle to achieve subsistence (Eyolf and Mvula 2007). Youth from better off households support their parents on their farms, while establishing themselves as independent adults along the way. However, most of the poorer youth have not been to school, some of them have completed secondary school, but are unable to find employment. A few young men escape this predicament and end up working in the sector as agents of NGOs, facilitating cooperatives or supporting access to credit. Most of these young men have at least completed their secondary education. 
The majority of women were relegated to the cultivation of other crops. It is, thus, against this backdrop that groundnut was described as a women's crop. In fact, Farm Radio International (2013) indicated that groundnuts in Malawi are mostly grown by small-scale, resource poor farmers, particularly women. During this period, women farmers typically devoted more land to groundnut than men and grew it as a subsistence crop. Farm Radio International (2013) concluded that groundnuts can be an important source of income, especially for women farmers, who have been mostly excluded from growing cash crops such as tobacco. It is not just women from female headed households that grow groundnuts, poor married women grew and still grow groundnuts to cater for subsistence, as well as for sale in the local markets to raise cash for basic household needs, especially salt, cooking oil, and milling maize.

Women groundnut farmers were, in some cases, joined by poorer male youth, who were struggling to establish themselves in life. The youth grow groundnuts as a means to raise income to improve their livelihood opportunities. Most of them intend to raise cash for building their own houses, or to raise capital to venture into the off-farm economy, especially petty trading. The major constraint for them, however, continues to be access to land. Most of the poorer youth are unable to access land from their families due to increasing pressure for land. Landholding per capita has diminished substantially over the past two decades to as low as 0.33ha (Chinsinga 2018; Moyo 2016).

Women who engaged in tobacco cultivation came from better off households as wives, daughters, and nieces (Chinsinga 2018; Masanjala 2006). Women participating in the cultivation of tobacco, who were either divorced or widowed, were also mostly from better off households. However, some of these women made their way up through entrepreneurship, supported by micro-finance institutions. They had decided to engage in tobacco cultivation as a means of diversifying their livelihood portfolio. Some of these women were government frontline workers and some were politicians in their own right or had links to influential people who opened up opportunities for them.

An assessment by Masanjala (2006), revealed that the majority of women were engaged in the tobacco value chain as middlemen. They purchased tobacco from the poorer farmers, cultivating on less than 1ha, and sold to better off farmers with direct access to the auction floors. The majority of poorer women, whether married, divorced, or widowed, worked as labourers or focused on the cultivation of other crops such as groundnuts. Some of the poorer men, their families, and the youth, especially male youth, cultivated tobacco on their small pieces of land to sell to either the middlemen or better off farmers. Young women, whether from poor or better off households, are completely marginalised. Of course, those with some education attempt to join the NGO circle, but very few are successful.

The social differentiation driven by burley tobacco took a different turn following the introduction of contract farming. There is a growing preference for the cultivation of tobacco under contracts because it allows merchants to meet manufacturers' compliance and traceability requirements. For tobacco to be competitive, farmers have to demonstrate the proper usage of chemicals and prove that it has been produced without exploiting child labour. Prowse and Grassin (2020) demonstrate how the introduction of the cultivation of tobacco under contracts has led to the deepening of social differentiation. Through the institutional arrangements that facilitate the cultivation of tobacco under contracts, a new social class has emerged. This class plays an intermediary role between the villagers growing tobacco and the outside world, or more precisely, the tobacco industry. Prowse and Grassin (2020) call members of this emerging social class brokers. Brokers generally act as the interlocutors for the leaf merchants and public institutions, such as the TCC.

Not everyone can qualify as a broker. They fit a particular profile. They are often members of a prominent family; have some political connections; are retired from public service or from security agencies; have a good reputation among smallholders; and serve as examples to the rest of tobacco farmers. The position of a club or zone leader within the integrated production system (IPS) enables the brokers to become the main gatekeepers for any smallholder farmer wishing to grow tobacco with a particular company. They thus become professionals of intermediation and occupy a privileged position at the juncture between the tobacco industry and the moral economy, which regulates village life (Prowse and Grassin 2020). Through local networks and regular meetings in town, these brokers strengthen their image as well-connected individuals and semiurban actors with all the associated and frequently misplaced connotations of modernity and progress. These brokers have, in some cases, become very important as the first point of call for villagers' contact with the outside world; to the extent that sometimes they even take precedence over chiefs. They have, in fact, usurped Ministry of Agriculture extension officers' roles, who are becoming less important than they once were in rural areas due to their limited resources. 
The emergence of brokers reveals that tobacco cultivation through contract farming has led to greater social differentiation within smallholder communities, reconfiguring power relations. Additionally, through the stringent requirements for compliance and traceability, contract farming tends to be exclusionary. Wealthier smallholders are able to shift to the IPS required by contractors, whilst poor households are often unable to meet these demands and are excluded from contract farming (Prowse and Grassin 2020). This is because wealthier smallholders are more likely to meet the conditions for obtaining contracts, such as cash deposits, financial credibility, and sufficient land to produce the demanded amount of tobacco.

These developments in social differentiation, to a great extent, underlie the enduring legacy of the one-party political settlement. Most of the families that emerged as serious tobacco farmers post liberalisation were beneficiaries of the rents dispensed during that era. The major beneficiaries of the rents from the monopoly of burley tobacco cultivation, until liberalisation in 1993, included politicians, high ranking civil servants, employees from parastatal organisations, and senior officials from security agencies, namely the Malawi Police Service and the Malawi Defense Force, and traditional authorities. Families connected to these elites had a head start when the cultivation of burley tobacco was liberalised (Chinsinga 2018). Following the transition to democracy, those who seized power sought to create similar opportunities for their families and patronage networks, focusing on commerce and industry as new avenues for the accumulation of wealth. This, in turn, has created a chain of patron-client relationships that pervade the entire system, privileging those with political, economic, and social ties to the ruling elites. These opportunities are somewhat extended to those who have some education or have demonstrated acumen in entrepreneurship through social ties. If an aspiring elite plays the game well, they might manage to open a door of opportunities for themselves as patrons, and thereby open up opportunities for their families, friends, or acquaintances. The underlying dynamics of the political settlement, in terms of creating winners and losers, has fundamentally remained the same, despite adapting to the demands of the multi-party electoral context.

\subsubsection{The emergence of medium-scale farmers}

The processes of social differentiation driven by burley tobacco are further exacerbated by the remarkable processes of structural agrarian change and transformation, through the emergence of medium-scale farmers (Answeeuw et al. 2016). Most respondents interviewed for this study noted that medium-scale farms have become a major force in Malawi's agricultural sector. In fact, according to Malawi's most recent official agricultural survey, medium-scale farms account for over a quarter of all land under cultivation. To put the development into proper perspective, for example, it is estimated that the area of land acquired by medium-scale farmers in the districts of Kasungu, Lilongwe, and Mchinji almost doubled between 2000 and 2015.

What makes this agrarian transformation even more interesting is the emerging pattern of ownership of these medium-scale farms. It is estimated that 54 per cent of the medium-scale landholdings resulted from the accumulation of land by small-scale farmers. The remaining 46 per cent are urban-based professionals, entrepreneurs, and civil servants, who have acquired land and started farming mid-life (Answeeuw et al. 2016). The emergence of this class of farmers is transforming the countryside in interesting ways. These farmers are pumping massive income from employment or business into the agricultural sector, triggering growth and development that may significantly alter the nature and pattern of rural-urban growth linkages. Through this agricultural growth trend an increasing number of smallholder farmers are losing their land, as they are selling it off and being displaced by this new class of farmers, who do not farm full-time and are often urban based. They are popularly referred to as weekend farmers (Chinsinga 2018).

In both modes of land accumulation to develop mediumscale farms, men dominate. A formal survey has not yet been carried out, but those interviewed for this study estimated that investors in these medium-scale farms are almost 90 per cent male. In both cases, these men are middle-aged with well-established careers, both in the private and public sectors. In rural areas, these men are linked to families described as belonging to the class of better off smallholder farmers. Most women involved in medium-scale farm development are single. These women are equally middle-aged, established businesswomen and/or active politicians, particularly MPs. In rural areas, the acquisition and consolidation of medium-scale farms is dominated almost entirely by men (Chinsinga 2018).

Both men and women have fairly equal chances of accumulating land to develop medium-scale farms, especially when it comes to purchasing land through the market. The major determinant in this regard is the ability to pay (Eyolf and Mvula 2007). Over the years, a market for customary land, although not formally recognised in law, has developed through which these transactions are mediated. The disproportionate number of men venturing into the medium-scale 
farming reflects the differential resource endowment between men and women. Men tend to be financially more empowered than women, but equally important is the fact that fewer women are aware of these opportunities (Jayne et al. 2019). In rural areas, even where land is inherited through women, the acquisition and consolidation of medium-scale farms is dominated by men.

The apparent upsurge in weekend farming is attributed, inter alia, to 'the realisation of the huge unexploited potential of the agriculture sector in the country and the increasing opportunities, especially in horticulture, legumes, and livestock'. ${ }^{45}$ Others simply think that, 'agriculture, especially for those in the public sector, offers a very good exit strategy into retirement as opportunities abound to rapidly accumulate wealth'. ${ }^{46}$ Most of these farmers are engaged in the production of seed for either legumes or maize, "which enables them to make quick money, since they have networks both in the public and private sector to get [a] premium price for their seed'. ${ }^{47}$ As a result of these developments, 'we are witnessing the rapid and massive displacement of villagers from land, especially in districts that are within $120 \mathrm{~km}$ radius of Lilongwe City'. ${ }^{48}$ These districts are therefore experiencing massive proletarianization, whereby the displaced villagers rely almost exclusively on their labour as a means of livelihood, working on land that they previously owned.

In the context of these developments, women and youth are particularly hard hit due to their weak control over land (Cook et al. 2014). While symbolically, women in matrilineal settings have control over land, they are not the principal decision makers when it comes to disposal of the land and the subsequent utilisation of the proceeds from land sales. These decisions are dominated by men (uncles, brothers, and husbands), which often has disastrous consequences for the livelihoods and welfare of women (Djurfeldt et al. 2018). The apparent weak control of land by women, even when ownership and control is traditionally vested in them, is largely due to inheritance practices. Even in matrilineal communities, inheritance of families' property (land, livestock, property etc.) is entrusted to male children, sometimes even when they are far younger than their elder sisters. This is further entrenched through the socialisation process. As the children are growing up, male children are frequently groomed as heirs to their fathers' estate. So, unlike the female children, the male children begin to learn about their father's property and related managerial skills at an early stage, which puts them in a better position to 'own' the property, including land. This is despite the fact that, traditionally, land is owned/or inherited through female members of the family. This explains why land acquisition and consolidation into medium-scale farms in the countryside is dominated by men. Poorer men often end up selling off their land to migrate to cities to look for better paying jobs. If they work in the same localities with women, they are able to bargain for better wages. Facing cultural obstacles, women's mobility is limited and, as such, they end up working in their respective localities, where they are often unable to bargain for better wages compared to men (Diguid and Weber 2016).

While the liberalisation of burley tobacco cultivation failed to work its magic, the emergence of mediumscale farmers is simply worsening the situation. All expectations that the liberalisation of burley tobacco cultivation could solve multiple policy priorities, such as improve food security, reduce expensive fertiliser subsidies, stimulate the non-farm rural economy, and even lead to crop diversification hardly materialised (Prowse and Grassin 2020). These failures have been compounded by smallholder farmers losing massive tracts of land to emerging farmers, who are dominating and monopolising the cultivation and sale of seed by exploiting their social, economic, professional, and political connections. From the study's interviews with key informants it was established that during the implementation of FISP, senior technocrats pushed for the liberalisation of seed supply to the programme beyond the certified members of the Seed Traders Association of Malawi (STAM). To ensure integrity, the policy initially directed that only members of STAM would supply seed to FISP. However, senior technocrats pushed for liberalisation to allow everyone to supply seed to the programme because most of them were producing seed, but were not members of STAM. For years FISP had been dealing in hybrid seed, but the technocrats pushed for the inclusion of the open pollinated variety (OPV) because most of them were producing this kind of seed and they made it cheaper compared to hybrid seed. For OPV maize seed, farmers did not pay any top-up for a pack of $7 \mathrm{~kg}$ seed, while farmers had to topup a $5 \mathrm{~kg}$ pack of hybrid seed, which in some cases cost as much as MK3,000. This ensured that most

45 Interview with the Acting Chief Executive Officer of FUM, 28 July 2020

46 Interview with a former official of NASFAM, 22 August 2020

47 Interview with an official of a multinational seed company in Malawi, 26 August 2020

48 Ibid. 
farmers went for OPV seed, not because of its quality, but rather because it did not require them to top-up. The displaced smallholder farmers, especially women, serve merely as a reservoir of cheap labour for the emerging medium-scale farms.

\subsection{Inside the groundnut value chailn}

\subsubsection{Barriers to entry into the value chain}

Both men and women can freely participate in the groundnut value chain if they so wish (Cook et al. 2014). However, women face barriers related to accessing sufficient land to participate in the value chain on a viable commercial scale. As highlighted in the previous section, women simply enjoy symbolic ownership and control of land. Key decisions about land, 'in terms of how to use it, [whether] to rent it out, or dispose [of] it altogether, and the use of the proceeds from the rentals or outright disposal, are made by men'. ${ }^{49}$ There are, of course, differentiated experiences among women in this regard. Independent women, who are relatively wealthier in their own right and/or come from better off families, do exercise control over their land. These women are able 'to venture into groundnut farming on a commercial scale, but these [women] are very limited, we can actually count them'. ${ }^{0}$

The majority of women, including those who are independent as widows or divorced, do not have practical control over their land to enable them to enter the groundnut value chain. They are not able to exercise control over land because 'most of them are disposed of their land, especially if they were staying at their husbands' villages, or they are simply too poor to make productive use of the land, even when they still have control over it'. ${ }^{51}$ Married women are often at the receiving end of decisions made by their husbands. Even among women, who are either widowed or divorced, but have male children who are over 20 years-old, "the decision making processes get transferred to these children, which further marginalises the women'. ${ }^{22}$ This means that compared to women and female youth, male youth - who also face barriers in accessing land - are slightly better off due to two interlinked factors: socialisation and inheritance practices (Djurfeldt et al. 2018).

Women are reportedly facing displacement from the groundnut value chain following the collapse of tobacco as a leading cash crop (Mgalamadzi 2018; Cook et al. 2014). As early as 2013, Farm Radio International observed that, 'men farmers are devoting more land to groundnuts, specifically growing it as a cash crop'. Thus, women appear to be losing their position in the value chain to men as groundnuts become more lucrative than tobacco or cotton, which were exclusively male domains. Following these developments, women are slowly but steadily participating in the groundnut value chain as labourers due to the dominance of men in the decision making positions at household level.

The key informant interviews undertaken for this study, as well as the relevant literature, suggest that groundnuts have evolved from being a crop that depends exclusively on family labour to a crop that now attracts hired labour. Both poor married and independent women find it very difficult to augment family labour with hired labour for groundnut cultivation, even though groundnut is re-emerging as a viable alternative cash crop to tobacco. In male headed households, women find it harder to use family labour on groundnut fields, especially if such cultivation is not supported or driven by their husbands. Both better off women (especially those who are independent) and men are able to hire additional labour to commercialise their groundnut farming because they have easy access to cash. However, most women are poorer compared to men, since they engage less in off-farm enterprises because they do not have the requisite capital and are restricted in their movements out of the homestead (Agar and Chalmers 2014). With the exception of youth from well off families, most of young men are unable to hire additional labour because they are struggling to become established in life and they are yet to accumulate enough wealth.

Both poor and better off women are constrained from participating in off-farm economic opportunities due to social and cultural considerations. In rural Malawi, the burden of domestic responsibilities, such as preparing food, taking care of children, and taking care of the sick, falls disproportionately on the shoulders of women (van Klaveren et al. 2009; Chinsinga 2004). One of the key informants for this study observed that:

The enduring challenge is that even when women are independent and they are in control of productive resources including land, they have been culturally conditioned to overdepend on men; they consult, if not, defer decision making to their older male children, brothers, or even uncles. (Interview with one of the traditional leaders in Ntchisi District, October 2018)

49 Interview with an official of a multinational seed company in Malawi, 26 August 2020

50 Interview with a traditional leader in Ntchisi District, October 2018

51 Interview with a traditional leader in Mchinji District, September 2018

52 Ibid. 
This observation has similarly been made by van Klaveren et al. (2009), who observed that one of the factors undermining women's empowerment is that they are culturally dependent on men for almost everything. This simply reinforces the dominance of women in the provision of labour in the agricultural sector. While women manage only about 26 per cent of farm plots, which are generally smaller than those managed by men, they provide 80 per cent of the labour for household food production (Cook et al. 2014).

\subsubsection{Value chain actors' ability to improve their performance}

Improving performance is key to gaining and capturing the benefits from a value chain. Existing evidence shows that women are more disadvantaged than men when it comes to factors that leverage one's performance in the groundnut value chain. Groundnuts are a labour intensive crop, involving numerous production, harvesting, and post-harvesting tasks, and women have limited access to labour compared to men in order to expand productivity. According to Cook et al. (2014), women are less able to command the labour of their spouses and their children, and, as such, they rely almost exclusively on their own labour. Women's ability to increase production is therefore largely constrained by limited access to labour.

Women's limited access to cash, through off-farm enterprises or credit facilities, further exacerbates barriers to increasing productivity. Expanding production of groundnuts will likely increase women's need for hired labour and labour saving technologies that can improve their productivity (Cook et al. 2014; Farm Radio International 2013). A study by Agar and Chalmers (2014) showed that in Malawi agricultural enterprises constituted only 25 per cent of the small and medium enterprises (SMEs). 'Only 4 out of 67 SMEs interviewed were primarily owned by women, though a few had husband and wife co-ownership, or another arrangement with the wife involved, but short of co-ownership' (Agar and Chalmers 2014: 20). Without ready access to cash women rely almost exclusively on their own labour for groundnut production and find it difficult to access productivity enhancing technologies especially seed.

More men than women participate in clubs or associations promoting the production of groundnuts. In some cases the participation of both men and women in these associations is almost the same, but men are still more likely to move into leadership positions (Cook et al. 2014). While both poor and better off women join clubs or associations, the poorer women are more marginalised than the better off women when it comes to decision making processes and leadership positions. Better off women are more likely to be considered for leadership positions than poorer women. However, this is usually for roles that are considered feminine, such as the secretary. According to some key informants for this study, poorer men have an edge over some better off women when it comes to leadership positions. This is attributed to the fact that culturally, more power is given to men than women.

The problem in Malawi is that culture gives more power to the husband. Even if the woman accesses the loan, the husband may be in charge to manage it, who is not a member of the cooperative. It ends up with most of the husbands using the loans not in most proper ways contributing to default. (Borda-Rodriguez and Vicari 2014:12)

Participation in farmer associations for groundnut is critical because it improves the social capital status of the members, which facilitates efforts to enhance productivity in the value chain. Through these clubs or associations, participants are able to increase their contacts; develop friendships and other relationships, which often lead to increased information and knowledge; create social safety nets; and improve their access to more tangible benefits, such as inputs. These benefits are more easily accessed by those in leadership positions (Prowse and Grassin 2020; Cook et al. 2014).

Efforts to establish women only clubs, associations, and even cooperatives, have been spearheaded by NGOs and some UN agencies, with support from various government departments and ministries (Borda-Rodriguez and Vicari 2014). Organisations such as NASFAM and FUM have also attempted to support women only associations, but these have not been very successful. This is attributed to several factors. The success of clubs or associations requires collective skills (to enable skills management, open discussion among members, the identification of a common vision, and access to training); networks (built on accountable leadership and interactions among clubs and associations); membership (built on a strong identity, education, cohesion and reciprocity, and a self-help attitude); and innovation (facilitated by the availability of capital and/or access to credit, participation in value chains, and Fairtrade). While research shows that women are more resilient and more focused on clubs or associations than men, they are often unable to deepen these prerequisites to make their clubs successful (Diguid and Weber 2016). This makes women only clubs or associations less able to benefit from the advantages that accrue from collective 
action within the groundnut value chain. Among other factors, this demonstrates that women's capacity to successfully navigate the association or club world is limited due to a lack of access to knowledge, training, education, and resources.

The youth, male and female, poor or better off, are excluded altogether from participating in farmer associations. This is because most of them do not own land. One of the requirements for membership is that participants should at least have access to a piece of land, either through direct ownership or renting. Most of the youth cannot raise enough money to afford land rentals and are still waiting in the wings to inherit land from their parents.

There are several pathways to improving performance in the groundnut value chain, but women and youth, especially those of from poorer families, are clearly disadvantaged in all of these pathways. Farmers' performance in the value chain can be improved by increasing production through land expansion, increased labour, and upgrading management skills. It can also be improved by securing new positions in the value chain, such as becoming a Lead Farmer, which is allocated in recognition of a farmer's improved performance and good standing in the community. It is estimated that the social differences outlined in this section lead to a productivity gap of 25 per cent between men and women (Cook et al. 2014). This calls for some action to combat social, cultural, and traditional norms that are oppressive to women. Overcoming these barriers would allow women to expand their roles beyond domestic and reproductive spheres.

\subsubsection{Value chain actors' ability to access and control benefits}

With the exception of better off independent women who are connected to better off families, most women do not access and control benefits from the groundnut value chain in the same way as men, even poorer men. This is primarily attributed to the differentiated roles that men and women play in the value chain (Farm Radio International 2013). There is a segregated division of labour within the groundnut value chain, with the participation of women concentrated in production and processing activities, whilst men's roles are mostly concentrated in marketing. Women perform most of the harvesting and post-harvesting tasks, such as digging out plants, removing pods from the plants, and the onerous work of shelling. In their study, Cook et al. (2014), observed that following the transformation of groundnuts into the equivalent of a cash crop, men now have more responsibility for sales and greater control over income. Consequently, men now dominate the decision making processes in terms of land usage (i.e. how much land to devote to the cultivation of groundnuts); the proportion of groundnuts to keep for home consumption and to be taken to the market; and the use of the proceeds from groundnut marketing. This weakens married, and even widowed or divorced, women's access to and control over the benefits from the value chain, which have emerged since the transformation of groundnuts into a potential alternative cash crop to tobacco.

Women are further disadvantaged when it comes to marketing, regardless of whether they are independent, better off, poor, or married. When women participate in the value chain in their own right, they often find it difficult to secure profitable markets for their groundnuts (Nyondo, Nankhuni and Me-ksope 2018). Women mostly sell their groundnuts to vendors, who purchase the groundnuts from them at farm gate prices. Since women do not often have lucrative alternative marketing outlets for groundnuts they endure the vendors' unscrupulous business tendencies. The vendors are known for offering extremely low prices and malpractices in tampering with weighing scales (Matita 2018; Mgalamadzi 2018). Due to the poor road transport network, the cost of transport in Malawi is very high, which in turn, hinders women's ability to access potentially profitable markets. Combined with women's disproportionate responsibility for domestic tasks, cultural taboos restricting women's movement away from the homestead, and concerns with the safety of some modes of transportation, women are left with vendors as their only reliable marketing outlet for their groundnuts. Women's ability to access more lucrative markets is further exacerbated by their lower literacy and numeracy levels. While potentially profitable markets might exist, women are unable to take advantage of them due to the aforementioned constraints, which make them more dependent on vendors for the marketing of groundnuts. Constraints on women's access to markets, thus, dramatically reduces their ability to secure and improve their position in the groundnut value chain and their access to and control of the benefits from the value chain (Cook et al. 2014).

The gendered division of labour in the groundnut value chain speaks to the social roles and expectations of men and women in Malawian society. Women are expected to dominate activities done within the homestead, whereas men are expected to venture out and interact with the outside world on behalf of their families. This explains why men dominate groundnut marketing activities while women are absorbed in production and processing activities. According to Diguid and Weber (2016), women are often limited to 
work in the so-called 'women's realm', such as care and domestic work, which makes them unable to effectively participate in off-farm economic activities, even when they are independent and better off socioeconomically. The paradox is that women's additional productive tasks do not lead to a lessening or sharing of tasks in the household with their male counterparts (ILO 2014). So, whether in poor or better off households, married or independent, women continue their roles in child rearing, family care, and household maintenance. The decisions, either in poorer or better off households, to hire additional labour are made predominantly by men, which may not fully take into account the needs of women. Traditional, cultural, and social conceptions of the roles of women and men and their expected behavioural patterns shape their respective roles and the division of labour in the groundnut value chain, which impacts their access to and control of the benefits from the value chain.

\subsubsection{Spotlight on the Mgona informal groundnut market}

The Mgona market is underpinned by a wide array of social differentiation processes. Strikingly, all buyers of groundnuts at this market are foreigners. No Malawian buyers directly participate in this market. There is, however, a hierarchy of buyers who are mostly Burundians. Some richer Burundians sub-contract less well-off Burundians to buy groundnuts for them for a commission. This appears to be a structured way of facilitating upward mobility for those who are new, or as a way of kick-starting young adults to live independent lives. During the fieldwork for this study, we encountered a young Burundian woman, who had just completed her secondary education. She had ventured into groundnut buying for a commission as a means to raise her college fees to study fashion and design: 'this is how our parents help us... you can choose to develop yourself into a competitive groundnut trader, or use it to raise resources to pursue a career or entrepreneurship of your choice'.

While the innovation of shelling machines has facilitated the growth of groundnut business, it also drives social differentiation, which determines the benefits accrued by different players in the market. All electric groundnut shelling machines are owned by Burundians, while most of the manual ones are owned by Malawians. The charges are higher for electric machines than for manual shelling machines. All the machine operators are men and all those engaged in sieving and grading groundnuts after shelling are women. Vendors supplying the Mgona market are also predominantly men. It is estimated that female vendors (who are mostly unmarried, divorced, or widowed and established businesswomen, having graduated from food vending) taking part in this market do not even make up 5 per cent of all suppliers. All groundnut buying agents commissioned by Burundians stationed in the villages are men. Women are involved largely as supporters to their husbands and not as principal points of contact and engagement. 


\section{THE MMPACT OF COVID-19 ON THE GROUNDNUT VALUE CHAIN}

\subsection{The political, economic and social context of the impacts of COVID-19}

The groundnut value chain has endured the devastating impact of the COVID-19 pandemic, but for this impact to be fully appreciated, it has to be placed in a broader context. In Malawi, the context in which the pandemic broke out is critical to understanding how the response was handled, as well as its consequences, particularly in terms of its impact on the agri-food system, generally, and the groundnut value chain specifically. The first COVID-19 case in Malawi was diagnosed the peak of political instability, following the nullification of the 21 May 2019 elections by both the Constitutional Court and the Supreme Court of Appeal, due to widespread, grave, and systematic irregularities. As a result of the nullification of these elections, the court ordered that FPEs be held within 150 days of the Constitutional Court verdict on 3 February 2020. This order was upheld by the Supreme Court of Appeal on May 8 2020.

The courts' determination did not please former President Mutharika, who was intent on using COVID-19 as a means to frustrate the holding of the FPEs as directed by the courts. He described the courts' rulings as tantamount to a judicial coup d'état of his government (Chinsinga and Mihowa 2020). Alongside these political developments, citizens galvanised by the Human Rights Defenders Coalition (HRDC) had been demonstrating against the government for nine consecutive months, demanding electoral justice. Citizens also used these demonstrations as an opportunity to voice their concerns on a number of other issues, such as deeply entrenched corruption in high places, nepotism, especially in recruitment in the public sector, collapsing service delivery in almost all sectors (including health, education, and agriculture), and worsening economic conditions, especially for those carrying out their trade in the informal sector.

Invoking the Disaster Preparedness and Relief Act, through a presidential directive, the government declared COVID-19 a national disaster and took all necessary steps to contain its spread. These measures, announced on 23 March 2020, included the closure of all schools; the barring of gatherings of more than 100 persons, including those in churches and for weddings and funerals; and the suspension of issuing visas to citizens of countries highly affected by the coronavirus. This was followed by the Minister of Health declaring COVID-19 a formidable disease under the Public Health Act, which gave the Minister authority to issue rules aimed at the control and suppression of infectious diseases. Based on this authority, the Minister of Health issued the Public Health (Coronavirus Prevention Containment and Management) Rules 2020 on 8 April 2020. These rules empowered the Minister of Health to impose a lockdown and outline the modalities thereof. Broadly speaking, the lockdown rules stated that all persons other than those exempted by the Minister must be confined to their place of residence. Exemptions to the rule included obtaining essential goods and services; seeking medical attention; visiting pharmacies, food supply stores, courts, or banks; and getting exercise, as long as no more than three persons exercise together.

A decision to implement a national lockdown, initially from 18 April to 9 May 2020, was made but it was never implemented. The announcement of the lockdown sparked spontaneous demonstrations and protests, especially among informal traders across the country (Mweninguwe 2020). The informal traders were opposed to the lockdown because it would create more hardship for them and their families in the absence of any livelihood support from the government. In the protests, some of the participants carried placards which, among other things, stated that: 'lockdown is more poisonous than coronavirus'; 'we would rather die of corona than die of hunger'. This is not surprising because the majority of Malawians struggle for daily subsistence, they live on a hand to mouth basis. Moreover, unemployment levels are extremely high, especially among the youth. In fact, an estimated 53 per cent of the 17.6 million people in Malawi live in abject poverty, according to official statistics (NSO 2018).

Besides the protests, a group of concerned citizens and the HRDC moved the courts to grant an injunction against the implementation of the lockdown. A judge 
of the High Court issued an injunction against the roll out of the lockdown measures on 17 April 2020, initially for seven days pending an inter-parte hearing. The judge agreed with the petitioners' argument that the government had failed to put in place measures to cushion the poor during the proposed lockdown (Chiuta 2020). The HRDC stated that, 'while we respect the health regulations regarding the lockdown, we want a lockdown that follows all laws and we do not want rights of vulnerable groups to suffer'. The concern about legal procedural irregularities in the conception and implementation of the proposed lockdown were further echoed by the Malawi Law Society. The judge further referred the case to the Constitutional Court because the issues raised by the petitioners required an interpretation of the Constitution.

The lockdown measures were, to a very great extent, resisted because of the citizens' perception that the former administration wanted to use the COVID-19 pandemic as a pretext to either delay or eschew altogether the FPEs mandated by the courts. The attempts by the former administration to frustrate the holding of the elections, as sanctioned by the courts, simply deepened the ruling's legitimacy during the crisis. According to Archard (2020), the legitimacy of a government deepens when a government suppresses the free flow of information; when it does not allow, empower, or capacitate independent institutions to check and validate its activities; when it does not enable citizens to independently organise to provide urgent services; when its data cannot be trusted; and when its officials, health professionals, or others, are afraid or prevented from speaking to power, and afraid to act decisively without strict orders from senior political leadership.

The impact of the COVID-19 pandemic in Malawi can be distinguished into two broad categories: the general impact on the economy and the specific impact on the agricultural sector. Even though Malawi did not formally implement a lockdown, the impact of COVID-19 has been severe. The COVID-19 pandemic measures that citizens have been asked to observe have had significant consequences. Some of these negative effects have been amplified by the lockdown measures implemented in countries that trade with Malawi, both within the region and even beyond. The agri-food sector in the country has been disproportionately affected by the COVID-19 pandemic because of the heavy reliance on agriculture by the majority of Malawi's population. About 80 per cent of the population is employed in the agricultural sector, which contributes around 33 per cent to GDP and accounts for over 90 per cent of foreign exchange earnings (AGRA 2020; Campbell 2020).

\subsection{The impacts of the COVID-19 pandemic on the economy}

A comprehensive assessment of the impact of the COVID-19 pandemic has been made by AFAP (2020). The main thrust of these diagnoses is that the COVID-19 pandemic has affected various sectors of the economy as a result of global and national actions. These actions have, in turn, disrupted the normal functioning of government, businesses, and people's lives. It is against this backdrop that preliminary assessments from IFPRI indicate that COVID-19 restrictions are likely to cause overall GDP losses of 11.6 per cent in Malawi. These estimates are based on the social accounting matrix multiplier model. This model also projected that, with the restrictions in April and May 2020, about 1.1 million people in Malawi would temporarily be pushed below the poverty line, mostly in rural areas.

AFAP's (2020) analysis showed that services have been most affected (-US\$155 million), followed by industry (-US\$48 million), and then agriculture (-US\$20 million). Agricultural GDP was projected to decline by 3.5 per cent, whilst agri-food systems were expected to contract by 8.2 per cent, largely due to the indirect impact of social distancing. During the presentation of the 2020/2021 budget in Parliament, the Minister of Finance announced a reduction of 35 per cent in revenue collection, from across all sectors, by Malawi's government due to the impact of the COVID-19 pandemic. It is against this backdrop that the government revised its economic growth forecast for 2020 downwards to 1.9 per cent, from an earlier projection of 5.1 per cent.

The analysis by the World Bank (2020) is even more comprehensive. The point of departure of this analysis from IFPRI's and AFRA's was that Malawi's economy was on a trajectory for its third year of faster growth in 2020, before the impact of the COVID-19 pandemic. The economy grew by 4.4 per cent in 2019, a marked increase from 3.5 per cent in 2018. In fact, real GDP growth was projected in September 2019 at 4.8 per cent. This was due to the expectation of the second consecutive year of strong harvests, offset by continuing political uncertainty, which weighed on business activity and investment.

The COVID-19 pandemic has affected the economy in five different ways (World Bank 2020). Disruptions to global value chains have affected the importation of key production inputs, especially from China, the EU, and South Africa, Malawi's key trading partners. This increased trade and logistics costs and delays. For instance, Malawi Revenue Authority customs data suggest that imports were 26 per cent lower in April and May 2020, than in the same period in 2019. The 
country is also suffering decreased demand in export markets. This is the case because key product markets are facing severe recessions, including the EU (which accounts for about 32 per cent of Malawi's exports), South Africa (where 10 per cent of Malawi's exports are sold), and the rest of Africa (which accounts 26 per cent of Malawi's exports). There has also been a significant decrease in tourism, even though it is not a major driver of growth as it is in East African countries. The decrease in tourism is expected to reduce GDP growth of services, such as transport (which contributes to about 2.9 per cent of GDP) and accommodation and food services (which contribute about 2 per cent of GDP). Last but not least, remittances have also decreased due to lower global economic activity. Remittances through money transfers decreased by 57 per cent in April 2020 and they have remained low since the outbreak of the pandemic. This could largely be attributed to strict lockdowns in South Africa, the largest source of Malawi's remittances.

\subsection{The iimpact of COVID-19 on the agri-food sector}

In the interviews conducted for this study, stakeholders focused on two key issues caused by COVID-19 that had negatively affected the groundnut value chain. Firstly, the pandemic has resulted in delays or serious disruptions to structured markets, or caused these markets to operate below optimum levels. Secondly, it has resulted in disruption and cancellation of postharvest field demonstrations, which help farmers to learn about how to take care of their groundnuts, especially in the context of the enduring aflatoxin challenge.

The first impact of the COVID-19 pandemic on the groundnut value chain was on the harvesting of groundnuts. The restriction measures were imposed towards the end of March 2020 and the first COVID-19 cases were diagnosed in the beginning of April 2020. This coincided with the harvest season for groundnuts, which runs from April through to June. These developments led to the panic harvesting of groundnuts, 'which means that most farmers did not strictly follow the basic guidelines that control aflatoxin'.53 Most farmers ended up experiencing substantial post-harvest losses and poor quality groundnut harvests, which fetched less than usual when offered for sale to buyers. Some of the farmers encountered serious losses because they abandoned harvesting groundnuts for fear of contracting the pandemic. Losses were particularly severe 'for farmers that grow groundnuts on [a] fairly larger scale and rely on hired labour to do the work'. ${ }^{54}$ Labour was not readily available as even those who generally offer labour were engaged in panic harvesting of their own crops, especially maize.

The pandemic affected the functioning of ADMARC markets, which most farmers, especially those in rural areas, depend on to sell their produce. This also affected the activities of private companies that groundnut farmers almost entirely rely on to sell off their groundnuts. The absence, delay, or suboptimality of these markets meant that households have had diminished access to income from crops, which are their main source of livelihood. This has been a double edged sword for farmers: 'farmers are losing income from either lack of, or existence of sub-optimal, markets, as well as increased costs due to delayed opportunities to sell. ${ }^{55}$ The markets for groundnuts were erratic due to the impacts of the preventive measures to control the pandemic. The COVID-19 preventive and control measures disrupted transport and related logistics services; the operational processing capacity of companies, severely limiting their business; and, in some cases, led to permanent business closures (AGRA 2020). The measures thus led to increases in transportation costs; most buyers postponing their missions as a means of respecting social distancing or simply choosing to work from home; and slackness in business, limiting the buyers' capacity to undertake purchases of crops.

The pandemic has further affected the operations of output markets due to the impacts on regional and international markets. This is the case, especially for exporters, because there is uncertainty in terms of whether their contracts will be honoured or not, there has been a scale down in produce stocking, and produce sale prices are below production costs. Farmers have been forced to sell produce at very low prices to middlemen and market brokers due to market closures. One of the respondents interviewed for this study emphasised that, "this has been hugely felt by groundnut farmers who rely on private traders to dispose of their groundnuts... the pandemic has limited the scope of activities of these traders because of rising transport costs occasioned by the pandemic'. ${ }^{56}$

While the impact of COVID-19 has generally been severe on the groundnut value chain, it has been disproportionately felt by women and the youth. Poor

53 Interview with an official of NASFAM, 1 September 2020

54 Ibid.

55 Interview with an official of one of the farmers' organisations, 28 August 2020

56 Interview with one of the emerging local commodity traders, 29 August 2020 
men, especially those who survive on petty trading and casual labour, have also been affected. As previously mentioned, women depend disproportionately on vendors to sell of their groundnuts. Most women have therefore not had access to markets as a result of the pandemic. In fact, vendors that will still trading were monopolised by men, who ordinarily venture out to seek lucrative markets, but were unable to do so because of the restrictions imposed by the COVID-19 control measures. It was also mostly women who were unable to fully harvest their fields due to labour constraints. These marketing dynamics for groundnuts have been captured by Matita and Chimombo (2020). In a survey, conducted between September and December 2020, Matita and Chimombo (2020) found that 64 per cent of the respondents stated that the number of traders doing business remained low. Furthermore, 50 per cent of respondents agreed that their ability to sell produce at both local markets and the farm gate had declined. This had prompted farmers who did have access to these markets, to sell a larger proportion of produce at a lower than usual price to fill income shortfalls from other sources. An AGRA (2020b) assessment reveals that the COVID-19 restrictive measures disproportionately affected women and youth in Southern Africa as they resulted in a severe loss of income and livelihood sources, following the closure and/or partial opening of informal business activities dominated by women and youth.

Campbell (2020) observed that lockdowns imposed by various countries have affected Malawi greatly, not only due to its landlocked nature, but also because it depends on imports of agricultural products and raw materials, which are used in the country. This has led to a shortage of agricultural inputs; increases in product and transport prices; low customer purchasing power; low agricultural input demand, leading to low sales; rising overhead costs etc. At the same time, it is important to note that the COVID-19 pandemic has become a fruitful business opportunity for well-established agri-SMEs that have been able to sell personal protective equipment, appropriate waste bins, water buckets, appropriate sanitizers and disinfectants, bulky farm produce etc. These SMEs have positioned themselves to work with local government, NGOs, and community based organisations to supply pertinent COVID-19 products and services (AFAP 2020).

Both farmers and agri-SMEs noted that COVID-19 has affected harvesting and winter demonstrations on topics such as post-harvest handling, chemical calibration and safe use, and winter cropping. One of the SME officials interviewed for this study observed that, 'post-harvest field days have been abandoned, which is a big blow because these field days act as both [a] learning and marketing platform for farmers and SMEs, respectively'. ${ }^{57}$ The field days serve as a marketing tool for existing and prospective farmers to appreciate, interact, and learn new farming techniques (Agriculture Direct Limited 2020). The COVID-19 pandemic has also negatively affected business by creating fear among farmers, which has resulted in most of them being afraid to purchase agri-inputs. This was attributed to the diminished market power of most farmers due to either the disruption, or the sub-optimal operation, of markets.

The pandemic has also greatly affected the provision of support services to the farmers (IFPRI 2020). These support services include extension systems, technical services, land administration services, and financial services. Officials from government extension and technical services have not been able to provide much support to farmers to help them achieve the best results due to restrictions on social distancing, movement, and office operations. Furthermore, due to the prioritisation of funding to health systems to support an increasing caseload of COVID-19 patients, which has resulted in reduced funding to agriculture, there have been fewer activities to support agricultural services.

The pandemic has, thus, affected agricultural inputs delivery, production systems, food security, and agricultural livelihoods. Emerging evidence from Malawi shows that the incidence of the pandemic has increased food insecurity and malnutrition, caused a loss of income, and resulted in declining livelihoods, especially for the majority of poor farmers in rural areas. According to WFP (2020), the number of households employing emergency livelihood based coping strategies is rising amid increasing prices of maize. A recently published fourth round WFP Mobile Vulnerability Analysis and Mapping (mVAM) on the effects of COVID-19 in Malawi indicates that about 30 per cent of surveyed households reported having employed emergency livelihoodbased coping strategies within the last seven days to access food. This is a rise from round three (17 per cent), round two (20 per cent), and round one (16 per cent) of the survey, conducted between January and December 2020 (Phiri 2020; WFP 2020). This is a clear demonstration that the restrictions associated with COVID-19 have put serious strain on budgets and household resources, impacting people's ability

57 Interview with an official of Agriculture Direct Limited, 2 September 2020 
to care for and nourish themselves and their families.

The WFP's findings are further reinforced by Matita and Chimombo (2020), who report increased food insecurity among households in Mchinji and Ntchisi districts between September and December 2020. This increased food insecurity has been caused by significant declines in purchasing power and food demand among low income households, due to the loss of income and livelihood sources, coupled with the erratic operations of informal markets. There have been heightened levels of food and nutrition insecurity among vulnerable populations such as women, youth, and casual labourers. The survey results show that more households reported running out of food and skipping meals in round 2 than in round 1 . The number of households running out of food increased from 54 per cent to 67 per cent, whilst those skipping meals increased from 57 per cent to 77 per cent. Fifty-four per cent of survey respondents reported spending an entire day without eating due to lack of money and other resources (Matita and Chimombo 2020).

The view of most respondents to this study is that Malawi should exploit the COVID-19 pandemic as an opportunity to build back better (Campbell 2020). The underlying argument is that the COVID-19 pandemic has demonstrated the fragility of Malawi's economy, which is underpinned almost exclusively by agriculture. The agriculture sector should be the starting point for the country to build back better and stronger. Baral, Das and Rustrick (2020) argue that the ultimate goal for Malawi should, therefore, be to build resilient farming communities. Communities become resilient if they are food and nutrition secure; are able to access and engage in reliable markets; are able to prioritise the well-being and participation of women and youth; and are able to withstand shocks, not only health shocks, but also those related to the climate, pests, and diseases. Strengthening the resilience of smallholder communities, who constitute over 2 million families and cultivate 4.5 million ha of land in Malawi, is critical to guaranteeing their food and nutrition security in the present and future. Failure to do so, will cause these communities to fall further behind and suffer serious consequences whenever shocks arise (AGRA 2020; Baral, Das and Rustrick 2020).

The belief is that by building a more robust agricultural system post-COVID-19, Malawi can grow its economy and be prepared for future crises. The priority policy prescription in this regard is towards the diversification of Malawi's agriculture sector. This will help to increase farmer incomes and improve nutritional outcomes, as well as help Malawi become more resilient to external shocks. Consequently, Campbell (2020), calls upon international donors, as well as agricultural companies and investors to partner with Malawi's government to promote system level change across the farming sector. This change should seek to improve the policy and regulatory environment, increase access to finance, and assist farmers in the transition from tobacco contract farming to high value horticulture and other crops. 
This paper has demonstrated that the groundnut value chain is a potentially significant alternative to the collapsing tobacco industry, but it is currently neglected by government, while being exploited by a cartel of traders (domestic and foreign), technocrats, and politicians for selfish interests. The story told in this paper explains the rise and fall of the groundnut value chain, as well as its re-emergence in a fundamentally reconstituted political, economic, and social context. Between the 1970s and 1980s, groundnuts were one of the leading cash crops exported to Europe, as well as regional markets, but this trade collapsed at the turn of the 1990s. Both production and exports of groundnuts collapsed due to the failure to contain aflatoxin contamination to acceptable levels, as demanded by the European market. Aflatoxin is regarded as a serious health hazard, which has the potential to cause liver cancer. The collapse of the groundnut value chain was exacerbated by the introduction of SAPs under the auspices of the World Bank and IMF, which fundamentally changed the institutional context for the groundnut value chain (Matita 2018; Mgalamadzi 2018). The reference to SAPs is still relevant three decades or so later, largely because of the enduring legacy that the policies have had on the country's ability to drive its development agenda, which have been informed by endogenous rather than exogenous considerations.

The stringent measures against excess aflatoxin levels in groundnut exports and the changing institutional environment propagated by the implementation of SAPs negatively affected the productivity of groundnuts. The cultivation of groundnuts among smallholder farmers declined following the liberalisation of the cultivation of tobacco, which fetched higher prices especially in the initial years. As a crop dominated by smallholder farmers, the shift to tobacco transformed groundnuts into a predominantly subsistence crop and essentially a women's crop (Farm Radio International 2013; NASFAM 2013). The implementation of SAPs targeted the restructuring of $A D M A R C$, particularly in terms of its scope of operations. ADMARC no longer provided smallholder farmers with ready access to inputs, such as improved groundnut seed varieties, and markets, particularly for those in remote areas. The structured and predictable market offered by ADMARC was replaced by vendors, who concentrate their activities in easy to reach areas and are known for their unscrupulous business tendencies. This largely disadvantaged women farmers, who are forced to rely on vendors as their primary market for groundnuts. The dominance of vendors as an alternative market for groundnuts also led to the collapse of grading as a prerequisite for selling groundnuts. Previously, ADMARC only bought from smallholder farmers who had carefully graded their groundnuts. The sale of ungraded groundnuts to vendors has made it very difficult for the groundnut export market to recover because this practice has progressively led to the deterioration of the quality of groundnuts.

There have been several efforts to revive the production, as well as the export, of groundnuts. These initiatives have been largely successful in terms of reviving groundnut productivity, but have failed to reclaim the share of the export market that collapsed at the turn of the 1990s. The revival in the productivity of groundnuts is attributed to several policy interventions, some of which are locally driven, while others are externally supported. However, the most notable policy in this regard is the NES (2012-2018). This strategy sought to promote legumes or oil seeds (groundnuts, soya beans, and pigeon peas) as a potential alternative to tobacco, as a leading foreign exchange earner, especially in view of the intensification of the anti-smoking lobby. The paradox, however, is that the designation of oil seeds as a potential alternative leading foreign exchange earner has not been matched by public investment to promote the progressive development of these value chains. Public investment to support, for example, ready access to seed for the crops is very limited. The existing seed system is largely supported by development partners, such as USAID and Irish Aid, which have been instrumental in the development of improved varieties. However, these improved varieties have not been made readily available to farmers.

As the groundnut value chain gains momentum as a potential alternative cash crop to tobacco, men are increasingly displacing women as principal actors in the value chain, especially with regards to marketing activities. There are several factors that are driving social differentiation within the value chain, which work predominantly against women. For example, 
compared to women, men have better access to and control over land, labour, credit, improved seed, knowledge (through clubs and often as association leaders), and even lucrative markets (Cook et al. 2014). This social differentiation within the groundnut value chain needs to be placed into the broader context of social differentiation processes in rural Malawi to be fully understood. There are two main processes driving social differentiation in rural Malawi, namely: the liberalisation of the cultivation of burley tobacco and the emergence of medium-scale farms, through both endogenous and exogenous forces. Building on the legacy of the one-party political settlement, the liberalisation of the cultivation of burley tobacco has created better off smallholders. These smallholders own more than 2ha of land and are connected to economically well-established families (comprising of retired public sector employees and successful local entrepreneurs); influential traditional leaders; political elites, especially the party in power; or, in some cases, are themselves, government frontline workers, such as teachers, field assistants, community development assistants etc. These better off smallholders are emerging as patrons and largely as interlocutors with the outside world, thereby monopolising opportunities associated with such engagements and propagating social differentiation. In addition, the accelerated development of medium-scale farmers is furthering the processes of social differentiation. The development of medium-scale farmers is led by the acquisition of land from desperate smallholders by middle-aged white collar employees, who are predominantly male and working in the private and public sectors. Farmers from better off families in rural areas are also buying up land to become medium-scale farmers. These mediumscale farmers are predominantly male because of the cultural, traditional, and social disadvantages that women face when it comes to inheritance and decision making processes at the household level.

Although not all women are disadvantaged, the findings of this study show that men are generally better off compared to women, especially within the framework of the groundnut value chain. Women who are independent (divorced, unmarried, and widowed), better off, and connected to influential families in politics, local leadership, and business, are able to assert themselves as key players in the groundnut value chain. Poorer men are also disadvantaged in the value chain, but poorer women are even worse off. Poor men usually have an advantage over their female counterparts in leadership positions in clubs or associations and decision making processes within the household, as well as in their ability to venture out of the homestead to engage with the outside world. Culturally, women are expected to defer to men and it is expected that women should spend most of their time undertaking domestic work, such as child birth, child care, household maintenance, and caregiving. Likewise, while the youth are marginalised, male youth are slightly better off than female youth. Male youth, especially those with some level of education, are able to explore opportunities in the informal economy, but the majority of their female counterparts are overburdened with domestic responsibilities, which are not often recognised as payable work. This greatly reflects the influence of Malawi's rural cultural disposition, whereby male children are groomed as potential heirs to their fathers' inheritance, which puts their female counterparts at a huge disadvantage when it comes to controlling resources.

The findings of this study demonstrate the impact of intersectionality on the welfare of women. Women are adversely affected in the groundnut value chain, not only because they are generally poorer than their male counterparts, but also because of the cultural, traditional, and social orientations that limit their sphere of action. Women are expected to carry out essentially all unpaid domestic work and they are not culturally expected to venture into economic activities that take them away from the homestead for prolonged periods without being sanctioned by the menfolk, even when they are not married. In cases where they are said to have control over land, women still cannot make critical decisions about it without deferring to their brothers, uncles, husbands, and even elder sons. The question of intersectionality applies to poorer men and youth as well. Poorer men tend to have limited access to land or are landless, usually depend on exploitative casual labour for employment, and are often disadvantaged in leadership positions, which are very key for social mobility in a context where patron-client relationships are dominant. The youth lack access to land in their own right, they cannot participate in clubs or associations, and cannot access lucrative markets when they manage to produce groundnuts. The impacts of COVID-19 have underscored the intersectionality of social differentiation, which affects the welfare of women, poorer men, and youth. These groups have not been able to access markets, even the informal ones, which have been largely monopolised by men who have better social capital networks that they can leverage in these difficult circumstances.

The study further demonstrates that there are winners and losers within the framework of the groundnut value chain, even though it is suffering neglect and only the chaotic informal markets are thriving. There is some contestation between and among actors with regards to the operation of export mandates, which, if properly implemented, would help to formalise commodity 
exports from the country. This, in turn, would enhance the proceeds that the country gets from agriculture, which are currently very low. While there seems to be general appreciation about the desirability of putting export mandates in place, there are contestations about exactly how this should be done. The positions of the key stakeholders, as discussed in this paper, show that each stakeholder group is bent on protecting their benefits, arising from the current configuration of the value chain. Behind the position of each stakeholder, there are specific interests that they want to promote, either by pushing for the export mandates to operate in a particular way, or avoiding the operationalisation of the mandates altogether. The interests of the different stakeholders are further evident in the operations of the Mgona informal groundnut export market. Mgona is a thriving market despite its obvious illegality. Both traders and government officials condemn it, but no concrete action has been taken to regulate it or abandon it altogether. While farmer organisations have attempted to bring up the issue of this market and its ramifications on the commodity market, it continues to operate within a $20 \mathrm{~km}$ radius from the seat of government and in the context of a newly operationalised CGA (2017). Under this Act, a trader in agricultural commodities is required to obtain an authorisation letter from the Ministry of Agriculture before applying for a license from the Ministry of Trade. This means that any trader who imports or exports licensable goods without a requisite license commits an offense punishable by law.

The experiences of the groundnut value chain in Malawi demonstrate that agricultural policy processes are inherently political. While policies that are implemented are broadly touted as being in the interest of smallholder farmers, or indeed, farmers more broadly, stakeholders at each stage in the value chain have particular interests that they want to promote, often for selfish interests and motives. The losers are almost always the smallholder farmers. This realisation, serves to emphasise that policies are often implemented, not because they are poised to make a difference to the livelihoods of Malawians, but because they will facilitate the extraction of rents and direct benefits for the political elite (Chinsinga 2018; Cammack 2010). The significance of PEA, therefore, is that it helps to identify and understand the political, economic, and social processes that promote or block pro-poor change, as well as the role of institutions, power, and the underlying policy context.

The fate of groundnut commercialisation in Malawi is a combination of several factors, but the watershed moment remains the introduction of SAP policy prescriptions. The responses to the debilitating effects of SAPs, coupled with the culture of opportunism and corruption inherent in the competitive clientelist political settlement, has led to the re-emergence of the groundnut value chain in an informal and chaotic context. This has led to the apparent strategic neglect and consequent capture of the value chain by a cartel of politicians, technocrats, and traders (local and foreign). So, while the groundnut value chain has tremendous potential as an alternative to the fledgling tobacco industry, this potential cannot be realised because of the perverse incentives that underpin Malawi's contemporary political economy. Through the groundnut value chain, this paper therefore demonstrates how different groups in society compete for and use resources, rents, and power at their disposal. The findings imply that the manner in which competition for and use of resources, rents, and power pans out, either leads to growth, transformation, and improved well-being, or stagnation and poverty (Prowse and Grassin 2020). 
AFAP (2020) Agri SMEs in Malawi in the Context of Covid-19: Impacts and Interventions (accessed 25 July 2020)

Agar, J. and Chalmers, G. (2014) Agribusiness SMEs in Malawi: Assessment of Small and Medium Enterprises in the Agriculture Sector and Improved Access to Finance in Malawi, Washington DC: United States Agency for International Development (USAID)

AGRA (2020) A Rapid Analysis of the Impact of the Covid-19 Pandemic on Selected Food Value Chains: Synthesis Report: AGRA Regional Food Trade and Resilience Programme, Nairobi: Alliance for a Green Revolution in Africa (AGRA)

Agriculture Direct Limited (2020) Malawi: The Voice of the Community in Malawi on the Impact of Covid 19 on Rural Livelihoods: The Case of Agriculture Direct Limited, Lilongwe: Agriculture Direct Limited

Answeeuw, W.; Jayne, T.; Kachule, R. and Kotsopoulos, J. (2016) 'The Quite Rise of Medium-Scale Farms in Malawi', Land MDPI 5.19: 12-28

Araujo, M.; Acosta, A. and Saiegh, S. (2004) Political Institutions, Policy Making and Policy Outcomes in Ecuador, Washington DC: Inter-American Development Bank: Latin America Research Network

Archard, D. (2020) Governance and International Society: Why Covid-19 Should Serve as a Wake-up Call? Washington DC: National Democratic Institute

Baral, A.; Das, A. and Rustrick, B. (2020) 'Covid 19 Highlights Need to Boost Resilience of Africa's Rural Poor', Devex, 4 May (accessed 25 July 2020)

Berry, S. (1993) No Condition is Permanent: The Social Dynamics of African Change in Sub-Saharan Africa, Madison: University of Wisconsin Press

Birner, R. and Resnick, D. (2010) 'The Political Economy of Policies for Smallholder Agriculture', World Development 38.10: 1442-1452

Booth, D. et al. (2006) Drivers of Change and Development in Malawi, Working Paper 261, London: Overseas Development Institute (ODI)

Borda-Rodriguez, A. and Vicari, S. (2014) The Malawian Cooperative Movement: Insights From Resilience, IKD Working Paper No. 969, Milton Keynes: The Open University

Cammack, D. (2010) 'The Politics of Chameleons Revisited: The Burden of Malawi's Political Culture', in M. Ott and E. Kanyongolo (eds.), Malawi's 2009 Parliamentary and Presidential Elections, Balaka: Montfort Media

Cammack, D.; Kelsall, T. and Booth, D. (2018) Review of Human Resource Management Reform in Malawi, Lilongwe: Department for International Development (DFID)

Campbell, J. (2020) 'Averting a Covid 19 Disaster in Malawi and Building Back Better', Council on Foreign Relations, 15 May, (accessed on 23 July 2020)

Chilundu, S. (2020) 'Ministry Moves to Control Illegal Imports, Exports', 24 July, The Nation, (accessed 28 November 2020)

Chimombo, M. (2018) 'Failed Promises: The Decline of Cooperative Membership in Malawi', Future Agricultures, 27 September (accessed 18 October 2020) 
Chinsinga, B. (2002) 'The Politics of Poverty Alleviation in Malawi: A Critical Review', in H. Englund (ed.), A Democracy of Chameleons: Politics and Culture in the New Malawi, Uppsala: Nordiska Africa Institute

Chinsinga, B. (2004) 'Poverty and Food Security in Malawi: Some Policy Reflections on the Context of Crumbling Traditional Support Systems', Canadian Journal of Development Studies 25.2: 321-341

Chinsinga, B. (2011) Agro-dealers, Subsidies and Rural Market Development in Malawi: A Political Economy Inquiry, Working Paper 31, Brighton: Institute of Development Studies (IDS)

Chinsinga, B. (2018) The Political Economy of Agricultural Commercialization in Malawi, APRA Working Paper 17, Brighton: Future Agricultures Consortium

Chinsinga, B. and Chasukwa, M. (2012) 'Youth, Agriculture and Land Grabs in Malawi', IDS Bulletin 43.6: 67-77

Chinsinga, B. and Mihowa, L. (2020) The Malawi June 232020 Elections: Some Reflections and Key Lessons, Oxfam in Malawi Briefing Paper, Lilongwe: Oxfam

Chinsinga, B. et al. (2020) Agricultural Commercialization and Rural Livelihoods in Malawi: A Historical and Contemporary Agrarian Inquiry, Zomba: Chancellor College and Bunda College

Chiuta, W. (2020) 'No Coronavirus Lockdown in Malawi as Court Maintains Injunction', Nyasatimes, 28 April (accessed 24 June 2020)

Clay, E. and Shaffer, B. (eds.) (1986) Room for Manoeuvre: An Explanation of Public Policy in Agriculture and Rural Development, London: Heinemann

Cook, K.; Manfore, C.; Kamoto, J. and Kalagho, K. (2014) Feed the Future: Integrating Nutrition in Value Chains, Malawi: Gender and Value Chain Assessment, Washington DC: United States Agency for International Development (USAID)

Crenshaw, K. (1989) 'Demarginalising the Intersection of Race and Sex: A Black Feminist Critique of Antidiscrimination Doctrine, Feminist Theory and Antiracist Politics', The University of Chicago Legal Forum 140: 139-167

Dancer, H. and Hossain, N. (2018) Social Difference and Women's Empowerment in the Context of the Commercialisation of African Agriculture, APRA Working Paper 8, Brighton: Future Agricultures Consortium de Sardan, O. (1999) 'A Moral Economy of Corruption in Africa?' The Journal of Modern African Studies 37.1: 25-52

Di John, J. and Putzel, J. (2009) Political Settlements Issues Paper, Birmingham University: Governance and Social Development Resource Centre (GSDRC)

Diguid, F. and Weber, N. (2016) Gender Equality and Women's Empowerment in Cooperatives: A Literature Review, Brussels: The International Cooperative Alliance

Djurfeldt, A.; Hillborn, E.; Mulwafu, W.; Mvula, P. and Djurfeldt, G. (2018) 'The Family Farms Together, the Decisions, However are Made by the Man: Matrilineal Land Tenure Systems, Welfare and Decision Making in Rural Malawi', Land Use Policy 70: 601-610

Dzanja, J.; Kamkwamba, H. and Matita, M. (2017) 'Assessing Market Prospects for Grain Legumes in Malawi', African Journal of Agricultural and Resources Economics 12.3: 2004-2016

Eyolf, J. and Mvula, P. (2007) Security for Many or Surplus for the Few? Customary Tenure and Social Differentiation in Southern Malawi, CMI Working Paper/2007, Bergen: Chr. Michelsen Institute

FAO (undated) 'Tobacco in Malawi' Food and Agriculture Organization (FAO) (accessed 10 October 2020)

FARA; ZEF and AICC (2015) Malawi: Potentials and Possibilities for German Collaboration in Agriculture, Bonn: Program of Accompanying Research Agricultural Innovation (PARI) 
Farm Radio International (2013) 'Groundnut Value Chain in Malawi, Production', Script 97.1, 14 November (accessed 21 September 2020)

Gondwe, A. and Baulch, B. (2017) The Case for Structured Markets in Malawi, Policy Note 29, Lilongwe: International Food Policy Research Institute (IFPRI) Malawi Strategy support Programme

Government of Malawi (GoM) (2012) The National Export Strategy (2012-2018), Lilongwe: Ministry of Economic Planning and Development

Government of Malawi (GoM) (2013) National Youth Policy, Lilongwe: Ministry of Youth and Sports:

Government of Malawi (GoM) (2018) Agriculture Sector Wide Approach (ASWAp), Lilongwe: Ministry of Agriculture and Food Security

Government of Malawi (GoM) (2018) Nutrition Policy, Lilongwe: Office of President and Cabinet (OPC)

Gray, H. (2019) 'Understanding and Deploying the Political Settlement Framework in Africa', World Politics. DOI:10:1093/acrefore/9780190228637.013.888

Hall, R.; Scoones, I. and Tsikata, D. (2017) 'Plantations, Outgrowers and Commercial Farming in Africa: Agricultural Commercialization and Implications for Agrarian Change', Journal of Peasant Studies 44.3: 515537

Helmke, G. and Levitsky, S. (2004) 'Informal Institutions and Comparative Politics: A Research Agenda', Perspectives on Politics 2.4: 725-740

Inclusive Business Action Network (2020) Pro-poor Peanut Processing in Malawi (accessed 22 April 2020)

ILO (2014) Leveraging the Cooperative Advantage for Women's Empowerment and Gender, Geneva: International Labour Organization (ILO)

International Trade Centre (2018) Exploring Malawi's Export Potential, Geneva: International Trade Centre

Itai, B. (2015) 'Information Gaps and Restricted Markets Frustrate Soya and Groundnut Farmers', Malawi News Agency, 28 May (accessed 22 April 2020)

Jayne, T. et al. (2019) 'Are Medium-Scale Farms Driving Agricultural Transformation in sub-Saharan Africa?' Agricultural Economics 501: 75-95

Keeley, J. and Scoones, I. (2003) Understanding Policy Processes: A review of IDS Research on Environment, Brighton: Institute of Development Studies

Khan, M. (2017) 'Political Institutions and the Analysis of Institutions', African Affairs 117.409: 636-655

Laws, E. and Leftwich, A. (2014) Political Settlements: DLP Concept Brief 01, Sydney: Developmental Leadership Programme

Lwanda, J. (2006) 'Kwacha: The Violence of Money in Malawi's Politics, 1954-2004', Journal of Southern African Studies 32. 3: 525-44

Masangati, I. (2016) 'Huge Market Boost for Soya, Groundnut Farmers across Malawi', Nyasatimes, 22 February (accessed 22 April 2020)

Masanjala, W. (2006) 'Cash Crop Liberalization and Poverty Alleviation in Africa: Evidence from Malawi', Agricultural Economics 35: 231-240

Matita, M. (2018) 'Groundnut Marketing in Malawi: A Review of Farmer Experiences', Future Agricultures (accessed 22 April 2020)

Matita, M. and Chimombo, M. (2020) Impact of Covid-19 on Food Systems and Rural Livelihoods in Malawi: COVID-19 Country Report 2, Brighton: Future Agricultures Consortium

Mgalamadzi, L. (2018) 'Groundnut Commercialization Trends in Malawi', Future Agricultures, 6 September (accessed 20 April 2020) 
Mhango, H. (2016) 'Malawi defies the anti-smoking lobby', African Business (accessed 10 October 2020)

Moyo, S. (2016) Family Farming in Sub-Saharan Africa: Its Contribution to Agriculture, Food Security and Rural Development, Working Paper Number 150, Brasilia: International Policy Centre for Inclusive Growth

Mweninguwe, R. (2020) 'Malawi Judge blocks Lockdown', D+C (accessed 30 June 2020)

NASFAM (2013) Groundnut Value Chain in Malawi: Challenges and Research Opportunities, Lilongwe: National Association of Smallholder Farmers of Malawi (NASFAM)

National Statistics Office (NSO) (2018) The National Population and Housing Census 2018, Zomba: Government Printer, Zomba

Norton, R. (2014) 'Agricultural Value Chain: A Game Changer for Smallholders', Devex, 28 July (accessed 16 September 2020)

Nyondo, C.; Nankhuni, F. and Me-ksope, N. (2018) Systematic Analysis of Groundnut Production, Processing and Marketing in Malawi, Policy Research Brief 64, Lilongwe: New Alliance Policy Acceleration Support (NAPAS)

O’Neil, T. et al. (2014) Fragmented Governance and Local Service Delivery, London: Overseas Development Institute

OECD (2011) Support State Building in Situations of Conflict and Fragility: Policy Guidance, DAC Guidelines and Reference Series, Paris: Organisation for Economic Cooperation and Development (OECD) Publishing

Phiri, G. (2020) 'Households in Coping Mechanism, Says WFP', 19 October (accessed 20 December 2020

Poulton, C. and Chinsinga, B. (2018) The Political Economy of Agricultural Commercialization in Africa, APRA Working Paper 16, Brighton: Future Agricultures Consortium

Prowse, M. and Grassin, P. (2020) Tobacco, Transformation and Development Dilemmas from Central Africa, London: Palgrave Macmillan

Rubin, D.; Manfre, C. and Nichol-Barret, K. (2009) Promoting Gender-Equitable Opportunities in Agricultural Value Chains: A Handbook, Washington DC: United States Agency for International Development (USAID)

Scott, L. and Chinsinga, B. (2018) Sustaining Poverty Escapes in Malawi: Policy Implications Brief, London: Chronic Poverty Analysis Network (CPAN), Overseas Development Institute (ODI)

Simtowe, F. et al. (2009) Assessment of the Current Situation and Future Outlooks for the Groundnut SubSector in Malawi, Lilongwe and Nairobi: International Crops Research Institute for Semi-Arid Tropics (ICRISAT)

Simtowe, F.; Longwe-Ngwira, A. and Siambi, M. (2012) 'Assessing the Competitiveness of Groundnut Production in Malawi: A Policy Analysis Matrix Approach', poster presentation at the International Association of Agricultural Economists (IAAE) Triennial Conference, Fog do Iguac, 24 August 2012

Smith, J. (2018) 'It is Time for Malawi to Quit Tobacco', The Conversation, 29 May (accessed on 15 October 2020)

UNCTAD (2019) Harnessing Agricultural Trade for Sustainable Development: Groundnuts, Sunflower and Soya Beans, Geneva: United Nations Conference on Trade and Development (UNCTAD)

UNIDO (2012) Malawi: Capacity Building for Aflatoxin Management and Control in Groundnuts, Vienna: United Nations Industrial Development Organization (UNIDO) Evaluation Group

Van Klaveren, M.; Todgens, K.; Hughie-Williams and Martin, N. (2009) An Overview of Women's Work and Employment in Malawi, Decision for Life MDG 3 Project Country Report No. 6, Amsterdam: Amsterdam Institute for Advanced Labour Studies

Wane, W. (2004) The Quality of Foreign Aid: Country Selectivity or Donor Incentives? Policy Research Work Paper No. 3325, Washington DC: The World Bank 
Wanyama, F. (2014) Cooperatives and Sustainable Development Goals: A Contribution to the Post 2015

Development Debate, A Policy Brief, Brussels: The International Cooperative Alliance and International Labour Organization (ILO)

World Bank (2018) Malawi: Systematic Country Diagnostics: Breaking the Cycle of Low Growth and Slow Poverty Reduction, Lilongwe: Malawi Country World Bank Team

World Bank (2020) Malawi Economic Monitor: From Crisis Response to a Strong Recovery, Lilongwe: Malawi World Bank Office

WFP (2020) Malawi Food Security Bulletin: Mobile Vulnerability Analysis and Mapping (mVAM) on the Effects of COVID-19 in Malawi-Round 4, Lilongwe: World Food Programme (WFP) 


\section{Annex 1: The hypotheses applicable to Malawi's groundnut value chain}

The three key hypotheses deemed applicable for Malawi, arising out of the work of Poulton and Chinsinga (2018), are as follows:

- If the country is landlocked, engagement in the value chain by national elites takes the form of acquiring land for crop production, seeking to secure reliable market outlets and prices for their produce through manipulation of state policies, and/or orchestrating the availability of cheap inputs (e.g. fertilisers), equipment (e.g. tractors), and services that they can 'capture'.

- If production of the crop primarily takes place in sub-national regions with high population density (greater than 200 persons per $\mathrm{km}^{2}$ ); production and sale for market are both dominated by smallholder farmers, despite the interest of larger players in entering the value chain. Conversely, where production of the crop primarily takes place in sub-national regions with low to medium population density (less than 200 persons per $\mathrm{km}^{2}$ ); medium and perhaps also large-scale farms have expanded their production and marketing of the crop dramatically over the past decade.

- If traditional development partners have engaged actively with the value chain over the past decade: policy interventions have both been designed to stimulate commercialisation in some form or another and to facilitate the participation of smallholder farmers in the resulting commercialisation processes.

The findings of this paper shed light on the three key hypotheses deemed applicable for Malawi as follows:

- With respect to the first hypothesis, groundnuts are not a major source of foreign exchange for Malawi in which case the second part of the hypothesis does not apply. As demonstrated in this paper, the production of groundnuts is dominated by smallholder farmers. It is estimated that as much as 93 per cent of groundnuts are produced by smallholder farmers, with the estate sector contributing the rest. There is, however, likely to be some significant changes to this structure of production in the near future, especially following the collapse of the tobacco industry. It was established during the fieldwork for this study that some tobacco companies are diversifying their portfolio to include the cultivation of groundnuts on a larger scale, for both domestic and export markets. Additionally, the emergence of medium-scale farms has exploded, especially in areas that are within $120 \mathrm{~km}$ radius of the capital city, Lilongwe. These medium-scale farms are dominated by elites, working largely in the public and private sectors (including those who have just retired from active service). The majority of these farmers are venturing into the production of seed, either for groundnuts or maize (Chinsinga 2018). This is a very lucrative business and most of them exploit the networks that they have within the public and private sectors. The reforms to FISP to allow non-STAM members to supply seed, especially OPV, are illustrative of the elite's capture of state policies to their advantage. Moreover, those in the public sector are mostly in policy making positions. There is evidence to suggest that these individuals strategically manipulate policies to ensure that they benefit their own farming activities. Some of these medium-scale farmers have ventured into the production of legumes, especially groundnuts and soya beans, to take advantage of export opportunities available under the auspices of NES. Prior to the adoption of the revised CGA (2017), the government had a tendency of implementing ad hoc export bans on essential commodities, especially maize and legumes, often on the pretext of protecting and guaranteeing 
food security. Yet, politically connected individuals and companies, including technocrats continued to export these commodities informally, getting premium prices. As discussed in this paper, these malpractices continue today, making it very difficult for the government to enforce its own legislative framework. While a potentially robust legislative framework exists, it is not effectively enforced because a cartel of politicians, technocrats, and traders systematically subvert it to promote their own selfish interests, goals, and objectives.

- With respect to the second hypothesis, the production of groundnuts indeed happens in areas of high population density. The production and sale for the market are dominated by smallholder farmers. While it is true that there is interest from medium-scale farmers in the groundnut value chain, they do not often produce groundnuts for formal marketing channels. These medium-scale farmers predominantly invest in the production of seed. The land that they use is not virgin land, land that has never been cultivated. They acquire it from smallholder farmers, who are, in turn, becoming landless and working on these farms as labourers. The majority of these smallholder farmers are women, particularly poorer, divorced, or widowed women, and a disproportionate share of this land is being grabbed from them and offered for sale. Of course, poorer men are selling off their land too (often less than 0.5ha) and the buyers are consolidating it. Existing statistics show that the magnitude of land ownership per capita has dramatically declined. It is estimated that 90 per cent of the smallholder farmers who cultivate groundnuts do so on less than 0.5ha. Besides the obvious question of land constraints, the scale of groundnut production is limited by its labour intensive nature and high seed density requirement (Nyondo, Nankhuni, and Me-ksope 2018). This high demand for labour and seed makes it very difficult for most smallholder farmers, who are poor, to cultivate groundnuts on more than 0.5ha, even when they may have adequate land at their disposal.

- With respect to the final hypothesis, efforts to promote the cultivation of groundnuts have been supported almost exclusively by traditional donors, namely, USAID and Irish Aid. Indeed, the ultimate goal of these donors has been to promote the involvement of smallholder farmers in the production of groundnuts and facilitate the value chain's ultimate commercialisation. Working with and through ICRISAT, these donors have supported efforts to make improved groundnut varieties available, which are disease resistant, high yielding, and have attributes that buyers look for, especially in exports. As pointed out in this paper, after the full-scale implementation of the SAP policy prescriptions, smallholder farmers have found it very difficult to access improved groundnut seed. As such, they have resorted to using local varieties, which are less productive, especially in the wake of variable and erratic climatic patterns (Simtowe et al. 2009). These donors have worked to produce breeder and foundational groundnut seed, but with very little success in terms of getting the seed into the hands of farmers on a large scale. The donors have also sought to improve the capacity of smallholder farmers to address the enduring problem of aflatoxin, which makes it very difficult for Malawian groundnuts to break into lucrative export markets. Public efforts to support the seed system have been limited compared to those directed at tobacco and maize, which are dominated by multinational seed companies. Government support is weak because groundnuts are not a major foreign exchange earner. The crop is not an important source of rent for the political elite, especially for purposes of cultivating and maintaining political support. The latest effort by USAID to support the groundnut value chain is through a programme called FtF-INVC, which aims to provide support and facilitate the expansion of access to markets for smallholder farmers involved in growing soya beans and groundnuts. 
- Interview with the Acting Chief Executive Officer of ADMARC

- Interview with a former official of NASFAM

- Interview with an official of NASFAM

- Interview with the Country Director of ICRISAT

- Interview with the Programme Manager of ICRISAT

- Interviews with members of GTAM

- Interviews with officials of GTAM

- Interview with the President of FUM

- Interview with a Chief Executive of a farmers' organisation

- Interviews with officials from various farmers' organisation

- Interview with the Coordinator of one of the government's supported agricultural projects

- Interview with one of the leading Agricultural Economists in Malawi

- Interviews with several officials from the Ministry of Agriculture

- Interview with the Manager of an agricultural commercialisation project supported by the World Bank

- Interview with the General Manager of Exageris

- Interview with an official of Agriculture Direct Limited

- Interviews with vendors at the Mgona informal groundnut export market

- Interviews with Burundian traders at the Mgona informal groundnut export market

- Interviews with several emerging local traders

- Interview with the Acting Chief Executive Officer of FUM

- Interviews with officials from multinational seed companies

- Interviews with several traditional leaders in Mchinji

- Interviews with several traditional leaders in Ntchisi 
Chinsinga, B. and Matita, M. (2021) The Political Economy of the Groundnut Value Chain in Malawi: Its Re-emergence Amidst Policy Chaos, Strategic Neglect and Opportunism, APRA Working Paper 56, Brighton: Future Agricultures Consortium

(c) APRA 2021

ISBN: 978-1-78118-791-3

DOI: 10.19088/APRA.2021.010

\section{(cC) BY-NC-ND}

This is an Open Access report distributed under the terms of the Attribution-Non Commercial-No Derivs 4.0 Unported (CC BY-NC-ND 4.0) Attribution - You must give appropriate credit, provide a link to the license, and indicate if changes were made. You may do so in any reasonable manner, but not in any way that suggests the licensor endorses you or your use. NonCommercial — You may not use the material for commercial purposes. NoDerivatives - If you remix, transform, or build upon the material, you may not distribute the modified material. You are free to: Share - copy and redistribute the material in any medium or format.

https://creativecommons.org/licenses/by-nc-nd/4.0/legalcode

If you use the work, we ask that you reference the APRA website (www.future-agricultures.org/apra/) and send a copy of the work or a link to its use online to the following address for our archive: APRA, Future Agricultures Consortium, University of Sussex,

Brighton BN1 9RE, UK (apra@ids.ac.uk)

\section{@creative}

All APRA Working Papers go through a review process before publication.

DO YOU HAVE COMMENTS ON THIS PAPER?

We would welcome your feedback on this working paper!

To provide brief comments, please follow this link to our short APRA Working Paper Feedback form: https://goo.gl/forms/1iVnXhhrIGesfR9

Agricultural Policy Research in Africa (APRA) is a programme of the Future Agricultures Consortium (FAC) which is

generating new evidence and policy-relevant insights on more inclusive pathways to agricultural

commercialisation in sub-Saharan Africa. APRA is funded with UK aid from the UK Foreign, Commonwealth \&

Development Office (FCDO) and will run from 2016-2022.

The APRA Directorate is based at IDS, UK (www.ids.ac.uk), with regional hubs at the Centre for African Bio-Entrepreneurship (CABE), Kenya, the

Institute for Poverty, Land and Agrarian Studies (PLAAS), South Africa, and the University of Ghana, Legon. It builds on more than a decade of

research and policy engagement work by the Future Agricultures Consortium (www.future-agricultures.org) and involves more than 100 researchers and communications professionals in Africa, UK, Sweden and USA. 